Yuying Fan, Liping Dong, Xueyan Liu, Hua Wang* and Yunhui Liu*

\title{
Recent advances in the noninvasive detection of high-frequency oscillations in the human brain
}

https://doi.org/10.1515/revneuro-2020-0073

Received July 14, 2020; accepted October 23, 2020;

published online December 25, 2020

\begin{abstract}
In recent decades, a significant body of evidence based on invasive clinical research has showed that highfrequency oscillations (HFOs) are a promising biomarker for localization of the seizure onset zone (SOZ), and therefore, have the potential to improve postsurgical outcomes in patients with epilepsy. Emerging clinical literature has demonstrated that HFOs can be recorded noninvasively using methods such as scalp electroencephalography (EEG) and magnetoencephalography (MEG). Not only are HFOs considered to be a useful biomarker of the SOZ, they also have the potential to gauge disease severity, monitor treatment, and evaluate prognostic outcomes. In this article, we review recent clinical research on noninvasively detected HFOs in the human brain, with a focus on epilepsy. Noninvasively detected scalp HFOs have been investigated in various types of epilepsy. HFOs have also been studied noninvasively in other pathologic brain disorders, such as migraine and autism. Herein, we discuss the challenges reported in noninvasive HFO studies, including the scarcity of MEG and high-density EEG equipment in clinical settings, low signalto-noise ratio, lack of clinically approved automated detection methods, and the difficulty in differentiating between physiologic and pathologic HFOs. Additional studies on noninvasive recording methods for HFOs are needed, especially prospective multicenter studies. Further research is fundamental, and extensive work is needed before HFOs can routinely be assessed in clinical settings; however, the future appears promising.
\end{abstract}

Keywords: electroencephalography; high-frequency brain oscillations; magnetoencephalography; noninvasive.

*Corresponding authors: Yunhui Liu, Department of Neurosurgery, Shengjing Hospital of China Medical University, Shenyang, China, E-mail: liuyh@sj-hospital.org; and Hua Wang, Department of Pediatrics, Shengjing Hospital of China Medical University, Shenyang, China, E-mail: wangh1@sj-hospital.org

Yuying Fan and Xueyan Liu, Department of Pediatrics, Shengjing Hospital of China Medical University, Shenyang, China

Liping Dong, Library of China Medical University, Shenyang, China

\section{Introduction}

High-frequency oscillations (HFOs) were first discovered and investigated using microelectrode arrays in the 1990s (Bragin et al. 1999b,c; Fisher et al. 1992; Huang and White 1989). In recent decades, there have been rapid advances in clinical research on HFOs. In 2006, Gotman and colleagues at the Montreal Neurological Institute published a milestone study in clinical HFO research, showing that HFOs could be recorded using ordinary clinical intracranial macroelectrodes (Jirsch et al. 2006). Following this breakthrough with macroelectrodes, rapidly growing numbers of studies on HFOs have been reported worldwide.

HFOs are defined as spontaneous brain activity that clearly stands out from the background signal that consist of at least four consecutive oscillations and frequencies $>80 \mathrm{~Hz}$ (Frauscher et al. 2017; Jacobs et al. 2012; Zijlmans et al. 2017). HFOs have been subdivided into ripples $(80-250 \mathrm{~Hz})$, fast ripples $(250-500 \mathrm{~Hz})$, and very fast ripples $(>500 \mathrm{~Hz})($ Bragin et al. 1999a; Brazdil et al. 2017; Usui et al. 2010; Usui et al. 2015). The majority of the current research on HFOs has used invasive intracranial electroencephalography (EEG), and only few prospective studies have been published (Hussain et al. 2016; Leung et al. 2018; Modur et al. 2011; Nevalainen et al. 2020; van 't Klooster et al. 2015). Evidence from these prospective studies suggests that fast ripple HFOs, in particular, are the primary biomarker of the seizure onset zone (SOZ). Many retrospective studies have corroborated that the resection of areas with high rates of HFOs is associated with favorable postsurgical outcomes (Fujiwara et al. 2016; Grinenko et al. 2018; Iimura et al. 2017; Leung et al. 2015; Liu et al. 2016; Pail et al. 2017). It has been reported that very fast ripples could be better predictors of epilepsy surgery outcomes than ripples or fast ripples; however, the fast ripples are detected only in a small percentage of patients (Brazdil et al. 2017; Usui et al. 2015). It has also been reported that disconnecting the high-frequency oscillation (HFO) networks could result in better seizure outcomes (Peng et al. 2018; van 't Klooster et al. 2017). It is important that HFOs are investigated using intracranial electroencephalography (EEG). However, this has limited the application of HFOs in patients with epilepsy, since intracranial EEG is an invasive procedure and in general, more expensive than scalp EEG. 
Detection of HFOs using noninvasive scalp EEG and Magnetoencephalography (MEG) was another milestone in human HFO research, providing a new way to investigate this brain activity in larger populations. In 2004, ictal high frequency activities (up to $100 \mathrm{~Hz}$ ) were first recorded using noninvasive scalp EEG in children with West syndrome experiencing epileptic spasms (Kobayashi et al. 2004). Similar findings were obtained for tonic seizure in LennoxGastaut syndrome (LGS) (Kobayashi et al. 2009). In 2010 and 2011, detection of interictal HFOs (ripple activity) was reported using scalp EEG in epileptic children and adults, respectively (Andrade-Valenca et al. 2011; Kobayashi et al. 2010). The first study that used MEG to detect HFOs in children with epilepsy was published in 2009 (Xiang et al. 2009). In the last 10 years, an increasing number of studies has been published on HFOs recorded using non-invasive methods. The clinical value of HFOs not only includes preoperative localization of epileptogenic regions, but also the assessment of disease severity, predicting seizures, evaluating treatment effects, and assessing epileptic susceptibility after brain injury. HFOs have been playing an increasingly important role in epilepsy, as well as in other disorders, such as migraine and autism. This article reviews the advances in noninvasive EEG and MEG research of HFOs in the human brain with an emphasis on pathologic HFOs in epilepsy. We also discuss the challenges in HFO research using non-invasive methods.

\section{Noninvasive HFO recording in epilepsy}

The 'standard' for noninvasive brain recordings depends on the desired temporal and spatial resolutions, as well as goal of recording (e.g. function or network mapping). EEG and MEG have high temporal resolutions. Functional magnetic resonance imaging (fMRI), with its low temporal resolution and high spatial resolution, has excellent utility in language/cognitive network mapping. Previously, it was commonly believed that HFOs could not be recorded using scalp EEG, owing to the thickness of the skull and the high electrical resistance that reduces intracranial electrical signal conduction. However, presently, it is generally accepted that HFOs can be recorded by scalp EEG provided the sampling rate is at least four times higher than the frequency band being analyzed (Worrell et al. 2008).

Most studies have reported only ripples, since the sampling rates (typically $512 \mathrm{~Hz}$ ) used were insufficient for fast ripple detection. Only a few studies have reported the recording of fast ripples (Bernardo et al. 2018; Pizzo et al. 2016). Studies have shown that HFOs recorded using scalp EEG originate from limited cortical regions (Cuello-Oderiz et al. 2017; Zelmann et al. 2014). Fast ripples may be generated from regions smaller than regions that generate ripples; thus, fast ripples are less likely to be recorded on scalp EEG (Ortiz et al. 2018). In the current literature, most studies on the evaluation of HFOs in epilepsy using scalp EEG have been conducted in children, with only a few conducted in adults. One mechanism that explains the noninvasive detection of scalp HFOs is that scalp HFOs may represent multiple, small generators activating asynchronously with temporal overlap (von Ellenrieder et al. 2016). The detection of scalp HFOs may also be possible because children have thinner skulls than adults (Wendel et al.2010).Studies have shown that the rates of scalp HFOs were considerably higher in children with epilepsy than in adults; however, there was no difference in the rate of intracranial HFOs between children and adults (Kerber et al. 2013; Kobayashi et al. 2015).

It has been established that EEG is sensitive to both tangential and radial dipolar sources when recording electrical brain activity, whereas MEG is sensitive to only tangential dipolar sources when recording neuromagnetic signals (Ahlfors et al. 2010). As the skull, scalp, and brain tissue have no effect on the penetration of magnetic field lines, MEG can theoretically record neural activity without reduction of signal conduction. MEG has been reported to have a much better spatial resolution in HFO research than scalp EEG (Hedrich et al. 2017). A survey of recent publications revealed that noninvasive HFO studies in patients with epilepsy were much more focused on the interictal state than the ictal state (Thomschewski et al. 2019). It remains a long-established fact that HFOs show variations during ictal and interictal states. Ictal HFOs are distributed in smaller areas than interictal HFOs in epilepsy, and better outcomes are achieved after the resection of the epileptogenic regions associated with ictal HFOs (Liu et al. 2015; Modur et al. 2011; Usui et al. 2011).HFOs have been investigated noninvasively in different conditions involving epilepsy, including West syndrome, LGS, childhood absence epilepsy(CAE), benign childhood epilepsy with centrotemporal spikes(BECTS), myoclonic epilepsy, Panayiotopoulos syndrome(PS), continuous spike-waves during slow-wave sleep(CSWS), insular epilepsy and tuberous sclerosis complex(TSC)

(Frauscher et al. 2017; Thomschewski et al. 2019). In the next sections, we present detailed findings of noninvasive HFOs obtained during ictal (See Table 1 and Table 2) and interictal states (see Tables 3 and 4). 


\section{Noninvasive recording of ictal HFOs in epilepsy}

\section{Noninvasive recording of ictal HFOs in refractory epilepsy syndrome}

Noninvasive recording of ictal HFOs was reported in two kinds of refractory epilepsy syndrome. Among related studies, most focused on West syndrome, and one was about LGS.As early as in 2004, Kobayashi et al. investigated high frequency activities (HFA) (frequency $>80 \mathrm{~Hz}$ ) during the ictal state of epileptic spasms in West syndrome (Kobayashi et al. 2004). In 2016, they also reported ictal fast oscillations (FOs) $(40-150 \mathrm{~Hz})$ during spasms which were associated with positive slow waves (Kobayashi et al.

Table 1: Ictal HFOs with scalp EEG recordings in epilepsy.

\begin{tabular}{|c|c|c|}
\hline Reference & Subjects & Value of HFOs/Findings \\
\hline $\begin{array}{l}\text { bayashi } \\
\text { al. } 2004\end{array}$ & $\begin{array}{l}11 \text { patients with West } \\
\text { syndrome, } 3 \text { months to } 4 \\
\text { years }\end{array}$ & $\begin{array}{l}\text { Scalp ictal high fre- } \\
\text { quencies(up to } 100 \mathrm{~Hz} \text { ) } \\
\text { correlation with the patho- } \\
\text { physiology of spasms }\end{array}$ \\
\hline $\begin{array}{l}\text { obayashi } \\
\text { al. } 2009\end{array}$ & $\begin{array}{l}20 \text { patients with LGS, } \\
3-29 \text { years }\end{array}$ & $\begin{array}{l}\text { Scalp high frequencies in } \\
\text { some ictal tonic seizures } \\
\text { indicating a common } \\
\text { generative mecha- } \\
\text { nisms with epileptic } \\
\text { spasms }\end{array}$ \\
\hline $\begin{array}{l}\text { watani et al. } \\
012\end{array}$ & $\begin{array}{l}4 \text { patients with symp- } \\
\text { tomatic West syndrome, } \\
9-14 \text { months }\end{array}$ & $\begin{array}{l}\text { Scalp HFOs of source loca- } \\
\text { tion consistent with neuro- } \\
\text { imaging findings of cortical } \\
\text { lesions in symptomatic } \\
\text { West syndrome }\end{array}$ \\
\hline $\begin{array}{l}\text { haitanya } \\
\text { t al. } 2015\end{array}$ & $\begin{array}{l}8 \text { children with CAE, } \\
1 \text { child with JAE, 6-10 } \\
\text { years }\end{array}$ & $\begin{array}{l}\text { The percentage of HFOs } \\
\text { was higher in ictal gener- } \\
\text { alized spike-wave dis- } \\
\text { charges compared to } \\
\text { interictal generalized } \\
\text { spike-wave discharges }\end{array}$ \\
\hline $\begin{array}{l}\text { obayashi } \\
\text { t al. } 2016\end{array}$ & $\begin{array}{l}11 \text { infants with west syn- } \\
\text { drome, } \\
\text { 3-9 months }\end{array}$ & $\begin{array}{l}\text { Ictal FOs related with the } \\
\text { generation of epileptic } \\
\text { spasms }\end{array}$ \\
\hline $\begin{array}{l}\text { Kobayashi } \\
\text { et al. } 2018\end{array}$ & $\begin{array}{l}21 \text { patients with } \\
\text { myoclonic epi- } \\
\text { lepsy,5 months to17 } \\
\text { years }\end{array}$ & $\begin{array}{l}\text { Ictal fast oscillations(FOs) } \\
\text { representing partially the } \\
\text { cortical pathophysiological } \\
\text { process of myoclonic } \\
\text { seizures }\end{array}$ \\
\hline $\begin{array}{l}\text { Ikemoto } \\
\text { et al. } 2020\end{array}$ & $\begin{array}{l}5 \text { patients with ASE, } 26 \\
\text { with CAE, } 15 \text { with JAE, } \\
5-11 \text { years }\end{array}$ & $\begin{array}{l}\text { Higher and frontal domi- } \\
\text { nant ictal ripples helping to } \\
\text { develop noval therapy } \\
\text { methods for ASE }\end{array}$ \\
\hline $\begin{array}{l}\text { Murai et al. } \\
2020\end{array}$ & $\begin{array}{l}\text { One patient with focal } \\
\text { epilepsy, } 77 \text { years }\end{array}$ & $\begin{array}{l}\text { Ictal HFOs after ictal DC } \\
\text { shifts deriving from the } \\
\text { acute focus of acute symp- } \\
\text { tomatic seizures }\end{array}$ \\
\hline
\end{tabular}

Table 2: Ictal HFOs with MEG recordings in epilepsy.

\begin{tabular}{|c|c|c|}
\hline Reference & Subjects & Value of HFOs/Findings \\
\hline $\begin{array}{l}\text { Xiang et al. } \\
2010\end{array}$ & $\begin{array}{l}4 \text { patients with focal } \\
\text { eilepsy, } 6-26 \text { years }\end{array}$ & $\begin{array}{l}\text { Ictal MEG HFOs localizing the } \\
\text { SOZ }\end{array}$ \\
\hline iao et al. 2014 & $\begin{array}{l}10 \text { children with } \\
\text { CAE, } 5-11 \text { years }\end{array}$ & $\begin{array}{l}\text { Ictal MEG HFOs localizing the } \\
\text { SOZ in CAE }\end{array}$ \\
\hline $\begin{array}{l}\text { Tenney et al. } \\
2014\end{array}$ & $\begin{array}{l}12 \text { children with } \\
\text { CAE, 6-12 years }\end{array}$ & $\begin{array}{l}\text { Ictal MEG HFOs within the } \\
\text { frontal cortical region } \\
\text { involved in the networks to } \\
\text { generating absence seizures }\end{array}$ \\
\hline Ing et al. 2016 & $\begin{array}{l}12 \text { children with } \\
\text { CAE, } 5-12 \text { years }\end{array}$ & $\begin{array}{l}\text { Ictal MEG HFOs correlating } \\
\text { with seizure severity in CAE }\end{array}$ \\
\hline $\begin{array}{l}\text { elmurugan } \\
\text { al. } 2018\end{array}$ & $\begin{array}{l}67 \text { patients with } \\
\text { drug-resistant focal } \\
\text { epilepsy, } \\
\text { 3-44 years }\end{array}$ & $\begin{array}{l}\text { Ictal scalp HFOs able to } \\
\text { localize the SOZ }\end{array}$ \\
\hline jiang et al. 2019 & $\begin{array}{l}15 \text { children with } \\
\text { CAE, } 5-11 \text { years }\end{array}$ & $\begin{array}{l}\text { The high-frequency- } \\
\text { dependent neural network is } \\
\text { involved to the neural } \\
\text { network dynamics for } \\
\text { absence seizure termination } \\
\text { in CAE }\end{array}$ \\
\hline Shi et al. 2019 & $\begin{array}{l}25 \text { children with } \\
\text { CAE, } \\
5-14 \text { years }\end{array}$ & $\begin{array}{l}\text { Ictal MEG functional network } \\
\text { at ripple band as a biomarker } \\
\text { of epileptic network in CAE }\end{array}$ \\
\hline
\end{tabular}

2016). These findings might suggest that neuronal firing related to FOs is relevant to the generation of epileptic spasms in West syndrome (Kobayashi et al. 2016). Although these two studies by Kobayashi et al. did not specifically study HFOs, brain activities higher than $80 \mathrm{~Hz}$ were evaluated. Iwatani et al. (2012) recorded HFOs by scalp EEG at spasm onset and concluded that the spatial source location of scalp ictal HFOs was consistent with the cortical lesions detected on neuroimaging in children with symptomatic West syndrome (Iwatani et al. 2012). Frequencies higher than $80 \mathrm{~Hz}$ was also investigated in another study by Kobayashi et al. which showed frequencies ranging from 43 to $101.6 \mathrm{~Hz}$ on ictal onset of tonic seizures in children with LGS (Kobayashi et al. 2009). Patients with West syndrome are mostly infants, whose skull bones are thinner, facilitating the recording of scalp HFOs. Spasm onset in West syndrome usually occurs in clusters; thus, ictal data are easily obtained. West syndrome may therefore be the ideal epilepsy syndrome for research on noninvasive detection of ictal HFOs.

\section{Noninvasive recording of ictal HFOs in generalized epilepsy}

Noninvasive recording of ictal HFOs was reported in generalized seizures, including childhood absence 
Table 3: Interictal HFOs with scalp EEG recordings in epilepsy.

\begin{tabular}{|c|c|}
\hline Reference & Subjects \\
\hline $\begin{array}{l}\text { Kobayashi } \\
\text { et al.2010 }\end{array}$ & $\begin{array}{l}10 \text { children with } \\
\text { CSWS,6-9 years }\end{array}$ \\
\hline $\begin{array}{l}\text { Andrade- } \\
\text { Valenca et } \\
\text { al.2011 }\end{array}$ & $\begin{array}{l}15 \text { patients with focal } \\
\text { epilepsy, } 19-63 \text { years }\end{array}$ \\
\hline $\begin{array}{l}\text { Kobayashi } \\
\text { et al. } 2011\end{array}$ & $\begin{array}{l}45 \text { BECTS and PS, 2-9 } \\
\text { years }\end{array}$ \\
\hline $\begin{array}{l}\text { Melani et al. } \\
2013\end{array}$ & $\begin{array}{l}32 \text { patients with focal } \\
\text { epilepsy, } 22-68 \text { years }\end{array}$ \\
\hline $\begin{array}{l}\text { Fahoum et al. } \\
2014\end{array}$ & $\begin{array}{l}22 \text { patients with focal } \\
\text { epilepsy,18-43 years }\end{array}$ \\
\hline Lu et al. 2014 & $\begin{array}{l}22 \text { patients with focal } \\
\text { epilepsy, } 25-53 \text { years }\end{array}$ \\
\hline $\begin{array}{l}\text { Zelmann } \\
\text { et al. } 2014\end{array}$ & $\begin{array}{l}11 \text { epilepsy patients with } \\
\text { FCD, } 17-52 \text { years }\end{array}$ \\
\hline $\begin{array}{l}\text { Chaitanya } \\
\text { et al. } 2015\end{array}$ & $\begin{array}{l}9 \text { children with child- } \\
\text { hood/juvenile absence } \\
\text { epilepsy, } 6-10 \text { years }\end{array}$ \\
\hline $\begin{array}{l}\text { Kobayashi } \\
\text { et al. } 2015\end{array}$ & $\begin{array}{l}17 \text { patients with West- } \\
\text { syndrome, } 3-9 \text { months }\end{array}$ \\
\hline $\begin{array}{l}\text { Toda et al. } \\
2015\end{array}$ & $\begin{array}{l}6 \text { infants with early } \\
\text { epileptic encephalopa- } \\
\text { thy, } 0-17 \text { weeks }\end{array}$ \\
\hline
\end{tabular}

Papadelis et 2 patients with epilepsy

al. 2016 with encephalomalacia,

11-15 years

Pizzo et al. 17 patients with genetic Concordance ripple with

2016 generalized and focal ep- clinical lateralization, difilepsy, 21-60 years ferential diagnosis

Pizzo et al., 10 patients with focal Association with SOZ

2016 epilepsy, 21-59 years

Qian et al. 14 children with child- Methylprednisolone

2016 hood epilepsy with cen- response monitoring trotemporal spikes, 4-11 ripple rates confirmed years

van Klink et 31 patients with focal and Ripples preceded epileptic al. 2016 multifocal epilepsy,

$18-76$ years

van Klink 22 patients with CSWS, Seizure prediction, differet al. 2016b 3-15 years

von Ellen- 17 patients with focal rieder et al. epilepsy, 19-68 years 2016

Cuello-

2017 epilepsy, $18-71$ years

entiation of atypical and typical

Localization association with clinical data (65\% sensitivity)

Compared superficial to

Mooij et al. 23 patients with different Comparison with controls

2017 types of epilepsy, 11

months to 14 years

Gong et al. 21 patients with CSWS, Concordance with lesions, $2018 \quad 4-13$ years higher atypical forms;

Table 3: (continued)

\begin{tabular}{|c|c|c|}
\hline Reference & Subjects & Value of HFOs/findings \\
\hline $\begin{array}{l}0 k \\
018\end{array}$ & $\begin{array}{l}\text { ts with focal } \\
, 3-42 \text { years }\end{array}$ & $\begin{array}{l}\text { Localization concordance } \\
\text { with clinical data (sensi- } \\
\text { tivity: } 55.4 \% \text {, specificity: } \\
72.2 \% \text { ) }\end{array}$ \\
\hline $\begin{array}{l}\text { Bernardo } \\
\text { et al. } 2018\end{array}$ & $\begin{array}{l}11 \text { children with TSC and } \\
\text { healthy controls, } \\
2 \text { months to } 5 \text { years }\end{array}$ & $\begin{array}{l}\text { Occurrence rates } \\
\text { comparing patients with } \\
\text { controls }\end{array}$ \\
\hline
\end{tabular}

Ikemoto et al. 25 patients with BECTS, Ripples rates and HFA $2018 \quad 2-9$ years identified atypical forms Kuhnke et al. 13 patients with HD EEG showing higher 2018 epilepsies of different ripple rates and better etiologies,8-52 years concordance with $\mathrm{SOZ}$

Mooij et al. 23 patients with different HFOs co-occurred with 2018 types of epilepsy, 11 sleep specific transients months to 8 years and HFOs rates during sleep

Boran et al. 11 children with 2019 drug-resistant focal epilepsy, 1-17 years Cao et al. 22 children with CSWS, 20196 years 9 months to 11 years 2 months

Scalp HFOs mirroring seizure frequency and disease severity in epilepsy Scalp HFOs as a biomarker of drug treatment response in CSWS

Dirodi et al. 6 children with medically Scalp HFOs-on-spikes to 2019 refractory epilepsy, be epileptogenic marker $5.4-16.2$ years

Insola et al. 3 patients with EPC and 2 Suppession of HF-SEP on 2019 patients with rolandic scalp EEG helping lesions without EPC understand the (non-EPC), 47-81 years pathophysiological mechanism of EPC

Kramer et al. 21 children with BECTS, Scalp ripples-on-spikes as 2019 4.9-14.9 years a predictor for seizure risk

in BECTS

Kuhnke et al. 24 children with focal Scalp HFOs assessing 2019 epilepsy( 15 of them also seizure outcome after with generalized tonic surgery clonic seizure), 14-63 years

Ohuchi et al. 10 with idiopathic CSWS, The high density of scalp 20194 with non-idiopathic ripples per spike in CSWS CSWS, 19 with BECTS,16 close relation to the with PS, 23 with other pathophysiology of the types of focal epilepsies, epileptic encephalopathy 22 with focal spikes in EEG without clinical seizures total 94 children, 1.3-12.2 years.

Toole et al. 9 patients with epilepsy Scalp HFOs recorded by 2019

van Klink

et al. 2019

30 patients with drug tEEG localizing $\mathrm{SOZ}$

Ferrari-Marresistant focal epilepsy, 8-54 years.

Scalp HFOs as a

biomarker of epileptogenicity

Scalp HFOs in comatose inho et al. with periodic discharges patients as a biomarker for 2020 in the EEG, 23-106 years the epilepsy risk subsequently developed 
Table 3: (continued)

\begin{tabular}{lll}
\hline Reference & Subjects & Value of HFOs/findings \\
\hline Tamilia et al. & Patients with refractory & Scalp ripples as a \\
2020 & $\begin{array}{l}\text { epilepsy, } \\
\text { prognostic biomarker for }\end{array}$ \\
Zhang et al. & 61 patients with BECTS, & $\begin{array}{l}\text { epilepsy surgery } \\
\text { Scalp HFOs as a biomarker }\end{array}$ \\
7-17 years. & for cognitive impairment \\
\hline
\end{tabular}

seizures and juvenile absence seizures. Scalp HFOs (80$250 \mathrm{~Hz}$ ) recorded by EEG were first studied in patients with absence epilepsy in 2015 (Chaitanya et al. 2015). Chaitanya et al. found that the percentage of ictal HFOs was higher in ictal generalized spike-wave discharges (GSWD) than in interictal GSWD (Chaitanya et al. 2015). Recently, Ikemoto et al. reported the features of HFA with ripple bands during ictal absence seizures in absence status epilepticus (ASE), CAE and juvenile absence epilepsy (JAE)(Ikemoto et al. 2020). This scalp EEG study concluded that ASE patients presented ictal ripples with higher power and frontal dominancy compared to CAE and JAE patients, which could help in developing a novel treatment method for ASE (Ikemoto et al. 2020). Using scalp EEG, Kobayashi et al. also studied ictal FOs during myoclonic seizures involving high frequencies (>80 Hz) (Kobayashi et al. 2018). This study suggested that the occurrence of myoclonic seizures was related with FOs, which partially represented the cortical pathophysiological process during myoclonus (Kobayashi et al. 2018).

Besides the analysis of ictal HFOs on scalp EEG, ictal HFOs recorded by MEG have also been investigated. Miao et al. studied ictal HFOs ranging from 80 to $500 \mathrm{~Hz}$ to locate seizure onset zones in CAE using MEG (Miao et al. 2014). The results suggested that seizure frequency was positively related to the rate of fast ripples and that compared to spikes, HFOs were focally localized in the medial prefrontal cortex (Miao et al. 2014). Tang et al. reported that ictal HFOs in the $200-1000 \mathrm{~Hz}$ range were significantly correlated with the number of daily seizures in CAE, which suggested that the HFOs could mirror the severity of absence seizures (Tang et al. 2016). A study by Tenney et al. on the networks generating absence seizures showed the presence of HFOs in the frontal cortical region in the ictal state (Tenney et al. 2014). Jiang et al. have identified the frequency-dependent neural network dynamics during the termination of absence seizures, with the results suggesting that the neural network dynamics at HFO bands for the termination of absence seizures in CAE involved both the cortices and the thalamus (Jiang et al. 2019). Recently, Shi et al.
Table 4: Interictal HFOs with MEG recordings in epilepsy.

\begin{tabular}{|c|c|c|}
\hline eference & Subjects & Value of HFOs/findings \\
\hline $\begin{array}{l}\text { gisberg } \\
\text { l. } 2008\end{array}$ & $\begin{array}{l}27 \text { patients with focal epi- } \\
\text { lepsy, } 17-67 \text { years }\end{array}$ & $\begin{array}{l}\text { HFA location and post- } \\
\text { surgical outcome } \\
\text { prediction }\end{array}$ \\
\hline $\begin{array}{l}\text { Xiang et al. } \\
2009\end{array}$ & $\begin{array}{l}30 \text { patients with lesional } \\
\text { epilepsy, } 6-17 \text { years }\end{array}$ & Identification of SOZ \\
\hline ampp et al. & $\begin{array}{l}6 \text { patients with focal epi- } \\
\text { lepsy, } 20-50 \text { years }\end{array}$ & Identific \\
\hline $\begin{array}{l}\text { Xiang et al. } \\
2010\end{array}$ & $\begin{array}{l}4 \text { patients with focal epi- } \\
\text { lepsy, } 6-26 \text { years }\end{array}$ & Ident \\
\hline Kiang et al. & $\begin{array}{l}10 \text { patients with childhood } \\
\text { absence epilepsy, 6-10 } \\
\text { years }\end{array}$ & $\begin{array}{l}\text { Proof-of-principle; } \\
\text { comparison with } \\
\text { controls }\end{array}$ \\
\hline $\begin{array}{l}\text { issen et al. } \\
016\end{array}$ & $\begin{array}{l}\text { atients with focal epi- } \\
y, 6-29 \text { years }\end{array}$ & $\begin{array}{l}\text { Correlation between } \\
\text { HFOs and spike sources }\end{array}$ \\
\hline & & \\
\hline 016 & $\begin{array}{l}\text { with encephalomalacia, } \\
11-15 \text { years }\end{array}$ & Identification of SOZ \\
\hline $\begin{array}{l}\text { ig et al. } \\
16\end{array}$ & $\begin{array}{l}12 \text { patients with childhood } \\
\text { absence epilepsy, 5-12 } \\
\text { years }\end{array}$ & $\begin{array}{l}\text { f HFO } \\
\text { th with } \\
\text { ity }\end{array}$ \\
\hline $\begin{array}{l}\text { an Klink et al. } \\
016\end{array}$ & $\begin{array}{l}\text { ients with focal epi- } \\
6-29 \text { years }\end{array}$ & $\begin{array}{l}\text { of irrita- } \\
\text { re }\end{array}$ \\
\hline $\begin{array}{l}\text { on Ellenrieder } \\
\text { al. } 2016\end{array}$ & $\begin{array}{l}\text { focal epi- } \\
\text { ars }\end{array}$ & $\begin{array}{l}\text { Localization concor- } \\
\text { dance with clinical data } \\
\text { ( } 47 \% \text { sensitivity) }\end{array}$ \\
\hline $\begin{array}{l}\text { gliorelli et al. } \\
17\end{array}$ & $\begin{array}{l}9 \mathrm{p} \\
\text { lep }\end{array}$ & tion with \\
\hline $\begin{array}{l}\text { van Klink et al. } \\
2017\end{array}$ & $\begin{array}{l}25 \text { patients with focal epi- } \\
\text { lepsy, } 4-29 \text { years }\end{array}$ & $\begin{array}{l}\text { Localization concor- } \\
\text { dance with resection } \\
\text { area in } 6 / 8 \text { patients }\end{array}$ \\
\hline an Klink 2018 & $\begin{array}{l}\text { focal epi- } \\
5\end{array}$ & $\begin{array}{l}\text { ation concor- } \\
\text { vith clinical data } \\
\text { cted area with } \\
\text { ecision }\end{array}$ \\
\hline $\begin{array}{l}\text { Dirodi et al. } \\
2019\end{array}$ & $\begin{array}{l}\text { medically } \\
\text { psy, }\end{array}$ & $\begin{array}{l}\text { HFOs-on-spikes } \\
\text { epileptogenic } \\
\text { r }\end{array}$ \\
\hline iang et al. & $\begin{array}{l}15 \text { children with CAE, } \\
5 y-11 y\end{array}$ & $\begin{array}{l}\text { Alteration of effective } \\
\text { connectivity at both } \\
\text { ripple and fast ripple } \\
\text { bands as a biomarker } \\
\text { for epilepsy networks in } \\
\text { CAE }\end{array}$ \\
\hline Meng 2019 & $\begin{array}{l}20 \text { epileptic patients( } 5 \\
\text { with CAE, } 8 \text { with TLE, } 4 \text { with } \\
\text { FLE, } 3 \text { with epilepsy type } \\
\text { not reported), } 7-17 \text { years }\end{array}$ & $\begin{array}{l}\text { Alteration of scalp HFO } \\
\text { networks as a } \\
\text { biomarker for epilepsy } \\
\text { networks }\end{array}$ \\
\hline $\begin{array}{l}\text { van Klink et al. } \\
2019\end{array}$ & $\begin{array}{l}30 \text { patients with drug } \\
\text { resistant focal epilepsy, } \\
8-54 \text { years }\end{array}$ & $\begin{array}{l}\text { Scalp HFOs as a } \\
\text { biomarker of } \\
\text { epileptogenicity }\end{array}$ \\
\hline $\begin{array}{l}\text { ugan } \\
019\end{array}$ & $\begin{array}{l}52 \text { patients with medically } \\
\text { refractory epilepsy } \\
\text { ( } 25 \text { with mesial temporal } \\
\text { lobe epilepsy and } 27 \text { with } \\
\text { focal neocortical epilepsy, } \\
10-43 \text { years }\end{array}$ & $\begin{array}{l}\text { Scalp HFOs enhancing } \\
\text { presurgical SOZ loca- } \\
\text { tion and postsurgical } \\
\text { outcome prediction in } \\
\text { medically refractory } \\
\text { epilepsy }\end{array}$ \\
\hline
\end{tabular}


Table 4: (continued)

\begin{tabular}{|c|c|c|}
\hline Reference & Subjects & Value of HFOs/findings \\
\hline Yin et al. 2019 & $\begin{array}{l}21 \text { patients with drug- } \\
\text { resistant insular epilepsy, } \\
12-47 \text { years }\end{array}$ & $\begin{array}{l}\text { Scalp ripples on spikes } \\
\text { locating SOZ in insular } \\
\text { epilepsy }\end{array}$ \\
\hline $\begin{array}{l}\text { Tamilia et al. } \\
2020\end{array}$ & $\begin{array}{l}\text { Patients with refractory } \\
\text { epilepsy, } \\
1.8-17.8 \text { years }\end{array}$ & $\begin{array}{l}\text { Scalp ripples as a } \\
\text { prognostic biomarker } \\
\text { for epilepsy surgery }\end{array}$ \\
\hline Yin et al. 2020 & $\begin{array}{l}22 \text { patients with refractory } \\
\text { insular epilepsy, } 12-47 \\
\text { years }\end{array}$ & $\begin{array}{l}\text { Pathologic scalp HFO } \\
\text { networks as a new } \\
\text { biomarker for epilepsy } \\
\text { networks in insular } \\
\text { epilepsy }\end{array}$ \\
\hline
\end{tabular}

observed that ictal ripples were mainly located in the medial frontal cortex in absence epilepsy, and the ictal MEG functional network at a frequency of $80-250 \mathrm{~Hz}$ was found to be an enhanced connection of the posterior cingulate cortex/precuneus with the frontal cortex (predominantly) (Shi et al. 2019).

Absence epilepsy could be considered a proper generalized epilepsy for the noninvasive detection of ictal HFOs. Compared to other seizure types (such as tonicclonic seizures), absence seizures may produce few artifacts during scalp EEG or MEG in ictal states. For MEG recordings, the ictal data of absence seizures are relatively easy to obtain because absence seizures usually have frequent onsets.

\section{Noninvasive recording of ictal HFOs in focal epilepsy}

Recently, Murai et al. reported for the first time that focal ictal direct current (DC) shifts and ictal HFOs after ictal DC shifts can be recorded together via scalp EEG at a sampling frequency of $500 \mathrm{~Hz}$, even with a time constant of $2 \mathrm{~s}$, as seen in their case report of a 77-year-old patient with focal epilepsy (Murai et al. 2020). As early as in 2010, data from four patients who experienced focal seizures during routine MEG tests were retrospectively studied by Jing et al. (Xiang et al. 2010). Ictal HFA recorded by MEG were consistent with the results of semiology and neuroimaging in all four patients, which may suggest the potential role of HFA in the noninvasive localization of the SOZ (Xiang et al. 2010). Recently, Velmurugan et al. have reported the recording of ictal MEG HFOs $(80-200 \mathrm{~Hz})$ in drug-resistant focal epilepsy patients; they were able to localize the SOZ with ictal HFOs, with a high sampling frequency and the use of other modalities (Velmurugan et al. 2018).

In general, ictal HFOs show stronger specificity for the SOZ than interictal HFOs. Many studies have proved that favorable and improved surgical outcomes are associated with surgical plans based on ictal HFO findings recorded by invasive EEG (Fujiwara et al. 2012; Leung et al. 2018; Modur et al.2011; Nariai et al. 2011; Ramachandran et al. 2008; Zijlmans et al. 2012). Liu et al. studied 13 patients with clinically suspected bitemporal epilepsy, by monitoring interictal and ictal HFOs using invasive EEG (Liu et al., 2016). The findings showed that ictal HFOs pointed toward the lateralization of the $\mathrm{SOZ}$, whereas conventional EEG and brain magnetic resonance imaging (MRI) failed to do so (Liu et al., 2016). Ictal HFOs and interictal HFOs were compared in a study by Zijlmans et al., and the findings showed that ictal HFOs may have more specificity for seizure onset zones (SOZs) than interictal HFOs, despite their similar locations (Zijlmans et al. 2011). However, it may be difficult to analyze HFOs using scalp EEG or MEG owing to the increase in artifacts during the ictal state, compared to that during the interictal state. Moreover, it is not easy to ensure patient availability for continuous MEG recording so as to obtain ictal data. For the above-mentioned reasons, compared to those on interictal HFOs, studies on the noninvasive detection of ictal HFOs in other epilepsy types (except for CAE and West syndrome) have been few.

\section{Noninvasive recording of interictal HFOs in epilepsy}

There are more studies on noninvasive interictal HFOs than on ictal HFOs. The studies on noninvasive interictal HFOs published before 2019 were described in a comprehensive review by Thomschewski et al. (Thomschewski et al. 2019). It has been reported that scalp interictal HFOs could reflect epileptogenesis, predict seizure activity, sensitively monitor the response to pharmacological treatment with methylprednisolone in CSWS and with adrenocorticotropic hormones in West syndrome, and could be associated with pathological brain networks; they could also be used to assess epileptogenic seizure risk post-brain injury (Thomschewski et al. 2019).Here, we describe the literature published on this topic since 2019.

\section{Value of scalp interictal HFOs in locating the SOZ and predicting surgical outcomes}

Kramer et al. studied 21 children with BECTS using HD-EEG with a 70-channel EEG cap at a sampling frequency of $2035 \mathrm{~Hz}$ (Kramer et al., 2019). The findings showed scalp interictal ripples-on-spikes as a biomarker of epileptogenicity, and interictal ripples-on-spikes outperformed 
spikes without ripples (Kramer et al. 2019). Scalp interictal HFOs are also very valuable in drug-resistant epilepsy. In a recent MEG study on insular epilepsy, Yin et al. reported that interictal ripples-on-spikes were valuable in locating the SOZ (Yin et al. 2019). Velmurugan et al. studied other medically refractory epilepsies (mesial temporal lobe epilepsy and focal neocortical epilepsy) and found that interictal MEG HFOs were useful as biomarkers not only for presurgical evaluation but also in the prediction of surgical outcomes (Velmurugan et al. 2019). By combining HD-EEG with simultaneous MEG recordings, scalp interictal HFOs have been considered as a noninvasive biomarker for the SOZ (Dirodi et al. 2019; van Klink et al. 2019). Tamilia et al. studied 20 children with refractory epilepsy using simultaneous HD-EEG and MEG recordings and demonstrated the value of scalp interictal HFOs in predicting the surgical outcome (Tamilia et al. 2020). Kuhnke et al. reported that scalp interictal HFOs combined with simultaneous intracranial recordings could easily identify children with poor surgical outcomes(Kuhnke et al. 2019).

\section{Value of scalp interictal HFOs in characterizing brain networks}

Currently, research on brain networks with regard to HFOs is a hot topic. Brain network alterations in the high frequency $(80-1000 \mathrm{~Hz})$ range recorded by MEG have been reported in 20 children with epilepsy(Meng, 2019). In a MEG study, Jiang et al. reported that the medial frontal cortex and deep brain areas were the sources of HFOs during interictal periods in CAE (Jiang et al. 2019). The effective connectivity from cortical regions to the thalamus has been strengthened at both ripple and fast ripple bands. In a MEG study by Yin et al., the interictal HFO-based effective connectivity networks were found to be altered in patients with insular epilepsy (Yin et al. 2020). Promisingly, abnormal HFO networks will likely become a new biomarker for epilepsy networks.

\section{Other applications of scalp interictal HFOs}

Zhang et al. studied 61 patients with BECTS and found that scalp interictal HFOs were more indicative of cognitive deficits than other abnormal EEG discharges (Zhang et al. 2020). Ohuchi et al. reported for the first time that the high density of ripples per spike in CSWS could be closely related to the pathophysiology of epileptic encephalopathy (Ohuchi et al. 2019). Cao et al., in a study of 22 children with CSWS, showed that scalp HFOs were an indicator of treatment response (Cao et al.2019). Boran et al. studied 11 children with drug-resistant focal epilepsy and observed that scalp HFOs could reflect seizure frequency and disease severity (Boran et al. 2019). Besides spontaneous HFOs, evoked HFOs have also been reported in EPC recently (Insola et al., 2019). Through scalp EEG recordings, Insola et al. found that significant suppression of high-frequency somatosensory-evoked potentials (HF-SEP) was helpful in understanding the pathophysiological mechanism of EPC (Insola et al. 2019). Evaluation of HFOs has also been used in comatose patients with periodic epileptic discharges in intensive care units (Ferrari-Marinho et al. 2020). Ferrari-Marinho et al. reported that scalp interictal HFOs indicated a latent brain structural lesion and could be a biomarker for the risk of subsequent development of epilepsy (Ferrari-Marinho et al. 2020).

\section{Noninvasive recording of HFOs in other pathologic conditions}

Besides epilepsy, HFOs have also been investigated in other diseases and disorders. In 2013, an MEG study in individuals with acute migraine headaches reported a taskelicited alteration of cortical activation (Xiang et al. 2013b). Patients with migraine showed increased spectral power in the $100-200 \mathrm{~Hz}$ range during ictal states (headache phases), but not during interictal states (pain free intervals). These findings may be important for developing new therapeutic interventions for migraine in the future (Xiang et al., 2013b).

Differences in cortical activation have been compared between ictal and interictal states in children and adolescents with migraine using low-to-high-frequency MEG signals. The results show that the source power of ictal HFOs $(65-150 \mathrm{~Hz})$ was significantly higher than that of the controls, whereas the source power of interictal HFOs was significantly lower than that of controls. These results suggest that the noninvasive assessment of cortical abnormality in migraine with MEG is feasible, and that novel therapeutic strategies for childhood migraine can be developed to focus on maintaining balanced cortical excitability (Xiang et al. 2013a). In 2016, a study reported quantitative neuromagnetic signatures of aberrant cortical excitability elicited by a finger tapping task in pediatric chronic migraine. The chronic migraine group showed increased spectral power between $100-200 \mathrm{~Hz}$ and $2200-2800 \mathrm{~Hz}$, suggesting that chronic migraines may be associated with elevated cortical excitability and aberrant activation from deep brain areas (Leiken et al. 2016). The spatial heterogeneity of cortical excitability during an auditory-motor task in adolescents with migraine has also been investigated using MEG recordings $(5-1000 \mathrm{~Hz})$ at 
both sensor and source levels. This study showed that high-frequency neuromagnetic signals were indicative of heterogeneous cortical activation in patients with migraine subjects as compared with controls. The degree of neuromagnetic heterogeneity of cortical activation was significantly correlated with headache frequency. These findings may be crucial for developing spatially-targeted strategies to normalize cortical excitability and treat migraine (Xiang et al. 2016b). These four migraine HFO studies by Xiang et al. are related to task states; therefore, future noninvasive research on resting state HFOs in migraine in needed.

In autism spectrum disorder (ASD), HFO localization of aberrant brain activity has been measured using wavelet and beamforming MEG methods. The results showed that patients with ASD generally had HFA $(90-2884 \mathrm{~Hz})$ in the frontal cortex and the source power of HFA $(200-1000 \mathrm{~Hz})$ in the frontal cortex in ASD was significantly higher than in controls. These findings suggest that elevation of intrinsic HFA in the frontal cortex may play a key role in ASD (Xiang et al. 2016a).

Recently, an MEG study reported an association between HFA in the visual cortex and emerging psychosis. This was the first comprehensive investigation into the oscillatory signatures during different stages of early psychosis. HFA is impaired in the visual cortex during emerging psychosis and may be linked to behavioral and clinical impairments. These findings suggest that MEG-aided measurement of neural oscillations could be used as a biomarker for clinical staging of emerging psychosis (Grent-'t-Jong et al. 2020). However, this study used limited frequencies, up to $90 \mathrm{~Hz}$; thus, future $\mathrm{HFO}$ studies on psychosis should include higher frequencies $(>90 \mathrm{~Hz})$.

HFOs have also been evaluated in patients with Parkinson's disease (PD). High-frequency cortico-basal ganglia oscillations have been investigated using implanted EEG electrodes (Hirschmann et al. 2017; Petersson et al. 2019). The findings showed that HFOs in the limbic circuits are associated with psychotic-like states; this observation provides an exciting new approach for evaluating new antipsychotic treatments. To date, no study has noninvasively assessed HFOs in PD.

\section{Challenges in noninvasive HFO research}

\section{Source scarcity in MEG, high density EEG (HD-EEG), and tripolar EEG (tEEG)}

When recording HFOs, it is necessary to consider the appropriate temporal and spatial sampling of signals. In general, there are three methods for noninvasive recording of HFOs: MEG, HD EEG, and tripolar EEG (tEEG). MEG has excellent spatial and temporal resolutions and is less affected by the skull and scalp, which makes it ideal for noninvasive HFO research. MEG is commonly considered as an add-on to basic diagnostic approaches, such as video EEG and MRI, and is mostly used to localize epileptic activities.

Compared to EEG, MEG has better performance in localizing epileptic regions (Velmurugan et al. 2018); however, traditional MEG is costly, and thus, have limited availability. A European survey published in 2016 found that MEG is performed in only 7 out of 25 epilepsy surgery centers (Mouthaan et al. 2016). In recent years, technological innovations in MEG have been ongoing. New MEG systems with optically pumped magnetometers (OPMs) are currently of great interest in research (Boto et al., 2019). These MEG sensors do not require cooling with liquid helium as traditional MEG systems do, which makes using these new MEG systems much less costly. OPMs is less affected by the head movement compared to conventional MEG, and can be worn more conveniently because of the sensors' positions on the scalp (Boto et al. 2019). Although OPMs is not yet used clinically, there have been some recent studies using OPMs in several areas (Barry et al. 2019; Borna et al. 2020; Boto et al. 2019; Elzenheimer et al. 2020; Hill et al. 2020; Iivanainen et al. 2020; Lin et al. 2019; Nardelli et al. 2019). OPMs has not yet been used in HFO research, but this is a very promising future application of this technology. Accordingly, we believe that introducing MEG into hospitals should be a priority to accelerate its use in noninvasive clinical HFO research.

It is commonly accepted that scalp EEG can record HFOs as long as the EEG electrodes are positioned correctly and the signal has a sufficient signal-to-noise ratio (SNR) (Zelmann et al. 2014; Zijlmans et al. 2017). It has been suggested the low rate of HFO detection on the conventional 10-20 electrode EEG system could be due to insufficient spatial sampling. The HD EEG system has a high sensor density, much like MEG. The denser mesh of electrodes is considered to be more sensitive to HFOs and local propagation patterns than conventional EEG (Besio et al. 2014; Menendez de la Prida and Trevelyan, 2011; Zelmann et al. 2014). Furthermore, HD EEG and MEG have better spatial resolution than conventional EEG and are capable of filtering spatial artifacts. To improve signal quality, tripolar concentric ring electrodes have also been reported to automatically attenuate muscle artifacts (Besio et al. 2014). Recently, it was reported that $\mathrm{EEEG}$, i.e. EEG recorded on the scalp with tripolar concentric ring electrodes, can detect HFOs (approximately $80-400 \mathrm{~Hz}$ ) that correlate with 
SOZs (Toole et al. 2019). The source localization of HFOs in tEEG may help clinicians identify epileptic brain regions or to determine the optimal location for intracranial recording (Toole et al. 2019). Both HD-EEG and tEEG currently have restricted accessibility, the possible reasons for which include high costs, patient discomfort in wearing the apparatus, and the data analysis being more timeconsuming than that for conventional scalp EEG. This seems to be a challenge for clinical HFO research presently.

\section{Low signal-to-noise ratio (SNR) in scalp EEG and MEG}

Typically low SNRs present a substantial challenge for HFO research. The reconstruction of signals through beamformer virtual sensors has been suggested as a spatial filtering method to increase the SNR (van Klink et al. 2016; van Klink et al. 2017). The OPMs system uses sensors positioned directly on the scalp; therefore, the SNR of the recording is relatively high due to the closeness, proximity of the sensors to the brain, with a good fit for all head sizes (Boto et al. 2019).

Suppression of sensor noise would significantly increase SNR for HFOs. A recent study investigated the validity of two temporal projection noise suppression algorithms for MEG measurements (Clarke et al. 2020).The findings showed that both oversampled temporal projection and temporal signal space separation effectively suppress noise in raw MEG data. These methods had the greatest joint effect in cases where SNR is low, or when detecting higher SNR single-trial responses from raw data. HFO signals are difficult to detect with noninvasive techniques due to low SNRs. Suppression of sensor noise would be especially beneficial to increase SNR for HFOs, which could help to improve the diagnosis and treatment of epilepsy (Clarke et al. 2020). The effects of muscle artifacts and removal of false HFOs should be accounted for in the evaluation of HFOs. A recent study reported that using two tools (with an EMG detector either on the scalp EEG or on the intracranial EEG) effectively alleviated the effects of muscle artifacts on HFOs (Ren et al. 2019). However, it is unknown whether this method can be applied to MEG or scalp EEG.

\section{Visual identification vs. automatic analysis}

The detection of HFOs after noninvasive recording is a challenging task. Although considered the gold standard for HFO detection, visual identification is highly time- consuming and subjective (Frauscher et al. 2017). There are controversial reports regarding the reliability of visual analysis (Spring et al. 2017, 2018). Furthermore, the variability in HFO rates and inconsistency in sources in recordings by long-term intracranial EEG make visual analysis more demanding (Gliske et al. 2018). Thus, it is essential to develop methods for the automatic detection for HFOs.

A variety of automated detectors have been developed in recent times (Gliske et al. 2016; Roehri et al. 2016; von Ellenrieder et al. 2012; Zijlmans et al. 2017). Automated detection of HFOs has shown a performance comparable with that of visual detection in locating the SOZ (Holler et al., 2015; Pail et al. 2013). Three classic automated methods of HFO detection have been validated and are widely used (Salami et al. 2012; Staba et al. 2002; Worrell et al. 2008). Recently, artificial intelligence (AI) with machine-learning techniques has been applied to the automated detection of HFOs (Schirrmeister et al. 2017). With AI encoding the features of signals after configuration optimization, the new automated detector outperforms other classic methods (Guo et al. 2018). Several HFO detection approaches have been developed in the form of MATLAB-based open-source tools. The RIPPLELAB software is a comprehensive application for visual and automatic HFO detection (Navarrete et al. 2016). MEEGIPS is a software to detect HFOs in a computer-assisted manner (Holler et al. 2019). When using softwares to detect HFOs, it is essential to verify that the right filter settings have been used. The detection of false-positive HFOs can be reduced by visual validation. However, false-negatives cannot be easily detected. The sensitivity and specificity of an automatic detector might vary based on the recording site and individual subjects.

An alternate technique to detect HFOs in the past was to identify HFA using spectral analysis (Xiang et al. 2009). This method can allow processing for long data periods or the processing of several data points at a time; it has been used in analyzing the majority of MEG HFO data (Velmurugan et al. 2019). It has also been demonstrated that beamformer virtual sensors can improve the visualization of MEG ripples (van Klink et al. 2016; van Klink et al. 2018). Lately, the combination of wavelet transform and Granger causality analyses for HFOs recorded via intracranial EEG has been reported to be accurate in suspecting bitemporal epilepsy (Han et al. 2019).

It is known that most clinicians read EEG traces on the screens but rarely look at raw MEG signals. Postprocessing of raw MEG signals is common, although the degree of postprocessing that is rational and feasible for clinical use remains unknown. Currently, there are no reliable 
automated detection methods that are easy to use and are validated by clinical trials. The use of an automated detection method alone is rather insignificant for noninvasive HFO research (Migliorelli et al. 2017; von Ellenrieder et al. 2012). Automated or semi-automated detection methods with broad applicability are crucial for noninvasive HFO research with MEG and scalp EEG (Zijlmans et al. 2017). It is recommended that automated detection techniques should be integrated into clinical review software, thus allowing for the validation of visual detection. However, further research is warranted for developing improved detection techniques.

\section{Distinction between physiologic and pathologic HFOs}

It has been widely reported that the healthy brain can produce HFOs in certain areas. Distinguishing physiologic HFOs from pathologic HFOs is both important and challenging. Previous studies using invasive EEG or a combination of invasive and scalp EEG have reported several different methods that can be applied to differentiate physiologic from pathologic HFOs.

Different coupling of HFOs in relation to slow waves during non-rapid eye movement (NREM) sleep has been shown to improve discrimination between physiologic and pathologic HFOs (Frauscher et al. 2015; von Ellenrieder et al. 2016). One invasive EEG study showed that both spontaneous occipital HFOs and epileptogenic extraoccipital HFOs were associated with delta phase activity, while the strength of delta-phase coupling decayed from 1-3 Hz in physiologic occipital HFOs (Nagasawa et al. 2012). Another invasive EEG study found that physiologic HFOs were more tightly coupled to slow waves of $0.5-1 \mathrm{~Hz}$, whereas epileptic HFOs were preferentially coupled with slow waves of 3-4 Hz (Nonoda et al. 2016). In addition to their different relationships with NREM sleep slow waves, physiologic and pathologic HFOs are differentially coupled to rapid eye movement (REM) sleep. Physiologic HFOs are more abundant, whereas epileptic HFOs are less frequent during REM sleep (Frauscher et al., 2016; Sakuraba et al. 2016). It has been reported that the rate of pathologic HFOs decreases with prolonged sleep duration, while physiologic HFOs increase during overnight REM sleep (von Ellenrieder et al. 2017). Distinctive relationships with interictal spikes have also been found: epileptic HFOs specific to the SOZ in the human neocortex are typically coupled with spikes while spontaneous physiologic HFOs outside of the SOZ do not often occur coincidently with spikes (Wang et al. 2013).
Evaluation of background EEG signal is another method for distinguishing between physiologic and pathologic HFOs. It has been shown that continuous HFOs on the oscillatory background EEG are typically physiologic (Melani et al. 2013), but HFOs on a flat background tend to be epileptic (Kerber et al. 2014).

Comparing the classical features of HFO morphology, including rate, amplitude, duration, and spectral frequency, is also a commonly used method (Alkawadri et al. 2014; Malinowska et al. 2015). Physiologic HFOs are considered to be mainly in the ripple frequency range, whereas fast and very fast ripples are more commonly, and perhaps even exclusively, associated with epilepsy (Alkawadri et al. 2014; Brazdil et al. 2017; Liu et al. 2018; Usui et al. 2015). Compared to epileptic ripples, physiologic spindle-linked ripples appear to be shorter and lower in amplitude (Bruder et al. 2017). As to the waveforms, HFOs linked to the $\mathrm{SOZ}$ are considered to have a high degree of consistency while HFOs in functional regions are more random (Liu et al. 2018).

Another method to identify HFOs as physiologic to is to purposefully evoke oscillations using tasks or stimuli. It has been reported that task-evoked physiologic HFOs have higher mean frequencies and shorter durations than epileptic HFOs (Matsumoto et al. 2013; Nagasawa et al. 2012). Although there are significant differences in classical features, as reported previously, the substantial overlap between the physiologic and pathologic HFOs should not be ignored.

Because of the distinct functions in different brain areas, physiologic HFOs can be classified into different types: memory-related HFOs, located in the hippocampus, parahippocampus, and entorhinal cortex; motor-related HFOs, located in the motor cortex and subthalamic regions; somatosensory HFOs, located in the somatosensory cortex and thalamic regions; and visually-evoked HFOs, located in the occipital lobe and visual cortex (Thomschewski et al. 2019). Compared to invasive EEG studies of physiologic HFOs, research using noninvasive techniques are limited. The first report on physiologic HFOs recorded with only scalp EEG was published in 2017(Mooij et al. 2017). In this study, the authors studied ripples in epileptic and healthy children with spike-free scalp EEGs during sleep. The findings showed that ripples occurring in normal EEGs of healthy children are considered physiologic, occurring mostly on the central and midline channels with a regular shape. By comparing the classic features of HFOs, physiologic ripples have been observed in children with epilepsy using scalp EEG, and these physiologic ripples are coupled with specific oscillations during sleep (Mooij et al. 2018). 
Overall, it is important to distinguish physiologic HFOs from pathologic HFOs. The varying associations of physiologic and pathologic HFOs with sleep should be considered during clinical evaluation. For example, when investigating pathologic HFOs during nonrapid eye movement (NREM) sleep, it has been recommended that HFOs should be recorded during the first occurrence of NREM in the night (von Ellenrieder et al. 2017). One should also be cautious while examining pathologic HFOs in the paracentral areas, hippocampus, and occipital cortex, since physiologic HFOs are most frequently seen in these areas (Thomschewski et al. 2019). It is not clear whether the invasive EEG methods used to distinguish physiologic HFOs from pathologic HFOs can be applied to noninvasive approaches; therefore, further noninvasive research on HFOs is needed. Phase-amplitude coupling of noninvasively detected HFOs has recently been demonstrated in epileptic spasms, suggesting that this may potentially be used to determine the pathogenicity of scalp-recorded HFOs (Bernardo et al. 2020).

\section{Conclusion}

Studies utilizing noninvasive recording of HFOs in the clinical setting with MEG and scalp EEG have contributed to the understanding and utility of HFOs as a biomarker of epileptogenicity. Compared to conventional EEG spikes, pathologic HFOs have been considered as a reliable biomarker for localizing the SOZ in symptomatic generalized epilepsy and focal epilepsy. Pathologic HFOs play an important role not only in guiding the scope and boundary of surgical resection and assessing surgical outcomes, but also in evaluating disease activity, the effects of drugs or treatments, and prognosis in epilepsy. Although research is scarce, pathologic HFOs have been investigated noninvasively using MEG in other diseases, such as migraine and autism. In a few noninvasive studies, physiologic HFOs (evoked or spontaneous) have also been reported using MEG or scalp EEG recordings.

Although there are many challenges facing noninvasive HFO research, especially regarding automatic detection, rapid advances in technology (e.g., AI) have the potential to address these problems in the future.

Moving forward, more high-quality, multi-center clinical studies with large sample sizes are needed to investigate HFOs with standardized examination. In particular, there is a need for properly designed, prospective, randomized multi-center trials.

Establishing objective and unified analysis methods for HFOs are expected to facilitate the development of standardized HFO assessment. With the advancement of MEG technology, it is anticipated that OPMs will become more widely used in clinical settings, making it easier to coordinate and implement noninvasive HFO studies with more participants. Noninvasive methods for evaluating HFOs provide new opportunities for both epilepsy research and other pathologic and physiologic conditions alike. In conclusion, we believe that there is a promising future for routine application of noninvasive HFO recording and analysis in clinical settings.

\section{Abbreviations}

$\begin{array}{ll}\text { AI } & \text { artificial intelligence } \\ \text { ASD } & \text { autism spectrum disorder } \\ \text { ASE } & \text { absence status epilepticus } \\ \text { BECTS } & \text { benign childhood epilepsy with centrotemporal spikes } \\ \text { CAE } & \text { childhood absence epilepsy } \\ \text { CSWS } & \text { continuous spike-waves during slow-wave sleep } \\ \text { DC } & \text { direct current } \\ \text { EPC } & \text { epilepsia partialis continua } \\ \text { ES } & \text { Epileptic spasm } \\ \text { FOs } & \text { fast oscillations } \\ \text { GSWD } & \text { generalized spike-wave discharges } \\ \text { GC } & \text { Granger causality } \\ \text { HD EEG } & \text { high density EEG } \\ \text { HFA } & \text { high frequency activity } \\ \text { HFOs } & \text { high-frequency oscillations } \\ \text { HF-SEP } & \text { high-frequency somatosensory evoked potentials } \\ \text { JAE } & \text { juvenile absence epilepsy } \\ \text { LGS } & \text { Lennox-Gastaut syndrome } \\ \text { MEG } & \text { mgnetoencephalography } \\ \text { MRI } & \text { magnetic resonance imaging } \\ \text { NREM } & \text { non-rapid eye movement } \\ \text { OPMs } & \text { optically pumped magnetometers } \\ \text { PS } & \text { Panayiotopoulos syndrome } \\ \text { PD } & \text { Parkinson's disease } \\ \text { REM } & \text { rapid eye movement } \\ \text { SNR } & \text { signal-to-noise ratio } \\ \text { SOZ } & \text { sizure onset zone } \\ \text { tEEG } & \text { tripolar EEG } \\ \text { TSC } & \text { tuberous sclerosis complex } \\ \text { WT } & \text { wavelet transform } \\ \end{array}$

Acknowledgments: We thank Prof. Jing Xiang (Director of MEG center, Division of Neurology, Cincinnati Children's Medical Center, USA) very much for revising and editing the manuscript.

Author contributions: All the authors have accepted responsibility for the entire content of this submitted manuscript and approved submission.

Research funding: This work was supported by the National Natural Science Foundation of China (81501299) 
and 345 Talent Project of Shengjing Hospital of China Medical University.

Conflict of interest statement: The authors declare that there is no conflict of interest regarding the publication of this article.

\section{References}

Ahlfors, S.P., Han, J., Belliveau, J.W., and Hamalainen, M.S. (2010). Sensitivity of MEG and EEG to source orientation. Brain Topogr. 23: 227-232.

Alkawadri, R., Gaspard, N., Goncharova, II, Spencer, D.D., Gerrard, J.L., Zaveri, H., Duckrow, R.B., Blumenfeld, H., and Hirsch, L.J. (2014). The spatial and signal characteristics of physiologic high frequency oscillations. Epilepsia 55: 1986-1995.

Andrade-Valenca, L.P., Dubeau, F., Mari, F., Zelmann, R., and Gotman, J. (2011). Interictal scalp fast oscillations as a marker of the seizure onset zone. Neurology 77: 524-531.

Barry, D.N., Tierney, T.M., Holmes, N., Boto, E., Roberts, G., Leggett, J., Bowtell, R., Brookes, M.J., Barnes, G.R., and Maguire, E.A. (2019). Imaging the human hippocampus with optically-pumped magnetoencephalography. Neuroimage 203, 116192. https://doi.org/10.1016/j.neuroimage.2019.116192.

Bernardo, D., Nariai, H., Hussain, S.A., Sankar, R., Salamon, N., Krueger, D.A., Sahin, M., Northrup, H., Bebin, E.M., Wu, J.Y., et al (2018). Visual and semi-automatic non-invasive detection of interictal fast ripples: a potential biomarker of epilepsy in children with tuberous sclerosis complex. Clin. Neurophysiol. 129: 1458-1466.

Bernardo, D., Nariai, H., Hussain, S.A., Sankar, R., and Wu, J.Y. (2020). Interictal scalp fast ripple occurrence and high frequency oscillation slow wave coupling in epileptic spasms. Clin. Neurophysiol. 131: 1433-1443.

Besio, W.G., Martinez-Juarez, I.E., Makeyev, O., Gaitanis, J.N., Blum, A.S., Fisher, R.S., and Medvedev, A.V. (2014). Highfrequency oscillations recorded on the scalp of patients with epilepsy using tripolar concentric ring electrodes. IEEE. J. Transl. Eng. Health Med. 2, 2000111. https://doi.org/10.1109/jtehm. 2014.2332994.

Boran, E., Sarnthein, J., Krayenbuhl, N., Ramantani, G., and Fedele, T. (2019). High-frequency oscillations in scalp EEG mirror seizure frequency in pediatric focal epilepsy. Sci. Rep. 9: 16560.

Borna, A., Carter, T.R., Colombo, A.P., Jau, Y.Y., McKay, J., Weisend, M., Taulu, S., Stephen, J.M., and Schwindt, P.D.D. (2020). Noninvasive functional-brain-imaging with an OPM-based magnetoencephalography system. PloS One 15: e0227684.

Boto, E., Seedat, Z.A., Holmes, N., Leggett, J., Hill, R.M., Roberts, G., Shah, V., Fromhold, T.M., Mullinger, K.J., Tierney, T.M., et al (2019). Wearable neuroimaging: combining and contrasting magnetoencephalography and electroencephalography. Neuroimage 201, 116099. https://doi.org/10.1016/j. neuroimage.2019.116099.

Bragin, A., Engel, J., Jr., Wilson, C.L., Fried, I., and Buzsaki, G. (1999a). Highfrequency oscillations in human brain. Hippocampus 9: 137-142.

Bragin, A., Engel, J., Jr., Wilson, C.L., Fried, I., and Mathern, G.W. (1999b). Hippocampal and entorhinal cortex high-frequency oscillations (100-500 Hz) in human epileptic brain and in kainic acid-treated rats with chronic seizures. Epilepsia 40: 127-137.

Bragin, A., Engel, J., Jr., Wilson, C.L., Vizentin, E., and Mathern, G.W. (1999c). Electrophysiologic analysis of a chronic seizure model after unilateral hippocampal KA injection. Epilepsia 40: 1210-1221.

Brazdil, M., Pail, M., Halamek, J., Plesinger, F., Cimbalnik, J., Roman, R., Klimes, P., Daniel, P., Chrastina, J., Brichtova, E., et al (2017). Very high-frequency oscillations: novel biomarkers of the epileptogenic zone. Ann. Neurol. 82: 299-310.

Bruder, J.C., Dumpelmann, M., Piza, D.L., Mader, M., Schulze-Bonhage, A., and Jacobs-Le Van, J. (2017). Physiological ripples associated with sleep spindles differ in waveform morphology from epileptic ripples. Int. J. Neural Syst. 27 1750011. https://doi.org/10.1142/s0129065717500113.

Cao, D., Chen, Y., Liao, J., Nariai, H., Li, L., Zhu, Y., Zhao, X., Hu, Y., Wen, F., and Zhai, Q. (2019). Scalp EEG high frequency oscillations as a biomarker of treatment response in epileptic encephalopathy with continuous spike-and-wave during sleep (CSWS). Seizure 71: 151-157.

Chaitanya, G., Sinha, S., Narayanan, M., and Satishchandra, P. (2015). Scalp high frequency oscillations (HFOs) in absence epilepsy: an independent component analysis (ICA) based approach. Epilepsy Res. 115: 133-140.

Clarke, M., Larson, E., Tavabi, K., and Taulu, S. (2020). Effectively combining temporal projection noise suppression methods in magnetoencephalography. J. Neurosci. Methods 341: 108700.

Cuello-Oderiz, C., von Ellenrieder, N., Dubeau, F., and Gotman, J. (2017). Influence of the location and type of epileptogenic lesion on scalp interictal epileptiform discharges and high-frequency oscillations. Epilepsia 58: 2153-2163.

Dirodi, M., Tamilia, E., Grant, P.E., Madsen, J.R., Stufflebeam, S.M., Pearl, P.L., and Papadelis, C. (2019). Noninvasive localization of high-frequency oscillations in children with epilepsy: validation against intracranial gold-standard. Conf. Proc. IEEE Eng. Med. Biol. Soc.: 1555-1558, 2019.

Elzenheimer, E., Laufs, H., Schulte-Mattler, W., and Schmidt, G. (2020). Magnetic measurement of electrically evoked muscle responses with optically pumped magnetometers. IEEE Trans. Neural Syst. Rehabil. Eng. 28: 756-765.

Fahoum, F., Melani, F., Andrade-Valenca, L., Dubeau, F., and Gotman, J. (2014). Epileptic scalp ripples are associated with corticothalamic BOLD changes. Epilepsia 55: 1611-1619.

Ferrari-Marinho, T., Perucca, P., Amiri, M., Dubeau, F., Gotman, J., and Caboclo, L.O. (2020). High-frequency oscillations in the scalp EEG of intensive care unit patients with altered level of consciousness. J. Clin. Neurophysiol. 37: 246-252.

Fisher, R.S., Webber, W.R., Lesser, R.P., Arroyo, S., and Uematsu, S. (1992). High-frequency EEG activity at the start of seizures. J. Clin. Neurophysiol. 9: 441-448.

Frauscher, B., Bartolomei, F., Kobayashi, K., Cimbalnik, J., van 't Klooster, M.A., Rampp, S., Otsubo, H., Holler, Y., Wu, J.Y., Asano, E., et al (2017). High-frequency oscillations: the state of clinical research. Epilepsia 58: 1316-1329.

Frauscher, B., von Ellenrieder, N., Dubeau, F., and Gotman, J. (2016). EEG desynchronization during phasic REM sleep suppresses interictal epileptic activity in humans. Epilepsia 57: 879-888.

Frauscher, B., von Ellenrieder, N., Ferrari-Marinho, T., Avoli, M., Dubeau, F., and Gotman, J. (2015). Facilitation of epileptic activity 
during sleep is mediated by high amplitude slow waves. Brain 138: 1629-1641.

Fujiwara, H., Greiner, H.M., Lee, K.H., Holland-Bouley, K.D., Seo, J.H., Arthur, T., Mangano, F.T., Leach, J.L., and Rose, D.F. (2012). Resection of ictal high-frequency oscillations leads to favorable surgical outcome in pediatric epilepsy. Epilepsia 53: 1607-1617.

Fujiwara, H., Leach, J.L., Greiner, H.M., Holland-Bouley, K.D., Rose, D.F., Arthur, T., and Mangano, F.T. (2016). Resection of ictal high frequency oscillations is associated with favorable surgical outcome in pediatric drug resistant epilepsy secondary to tuberous sclerosis complex. Epilepsy Res. 126: 90-97.

Gliske, S.V., Irwin, Z.T., Chestek, C., Hegeman, G.L., Brinkmann, B., Sagher, O., Garton, H.J.L., Worrell, G.A., and Stacey, W.C. (2018). Variability in the location of high frequency oscillations during prolonged intracranial EEG recordings. Nat. Commun. 9: 2155.

Gliske, S.V., Irwin, Z.T., Davis, K.A., Sahaya, K., Chestek, C., and Stacey, W.C. (2016). Universal automated high frequency oscillation detector for real-time, long term EEG. Clin. Neurophysiol. 127: 1057-1066.

Gong, P., Xue, J., Qian, P., Yang, H., Liu, X., Cai, L., Bian, K., and Yang, Z. (2018). Scalp-recorded high-frequency oscillations in childhood epileptic encephalopathy with continuous spike-and-wave during sleep with different etiologies. Brain Dev. 40: 299-310.

Grent-'t-Jong, T., Gajwani, R., Gross, J., Gumley, A.I., Krishnadas, R., Lawrie, S.M., Schwannauer, M., Schultze-Lutter, F., and Uhlhaas, P.J. (2020). Association of magnetoencephalographically measured high-frequency oscillations in visual cortex with circuit dysfunctions in local and large-scale networks during emerging psychosis. JAM. Psychiatry.

Grinenko, O., Li, J., Mosher, J.C., Wang, I.Z., Bulacio, J.C., GonzalezMartinez, J., Nair, D., Najm, I., Leahy, R.M., and Chauvel, P. (2018). A fingerprint of the epileptogenic zone in human epilepsies. Brain 141: 117-131.

Guggisberg, A.G., Kirsch, H.E., Mantle, M.M., Barbaro, N.M., and Nagarajan, S.S. (2008). Fast oscillations associated with interictal spikes localize the epileptogenic zone in patients with partial epilepsy. Neuroimage 39: 661-668.

Guo, J., Yang, K., Liu, H., Yin, C., Xiang, J., Li, H., Ji, R., and Gao, Y. (2018). A stacked sparse autoencoder-based detector for automatic identification of neuromagnetic high frequency oscillations in epilepsy. IEEE Trans. Med. Imag. 37: 2474-2482.

Han, T., Xu, Z., Du, J., Zhou, Q., Yu, T., Liu, C., and Wang, Y. (2019). Ictal high-frequency oscillation for lateralizing patients with suspected bitemporal epilepsy using wavelet transform and granger causality analysis. Front. Neuroinf. 13: 44.

Hedrich, T., Pellegrino, G., Kobayashi, E., Lina, J.M., and Grova, C. (2017). Comparison of the spatial resolution of source imaging techniques in high-density EEG and MEG. Neuroimage 157: 531-544.

Hill, R.M., Boto, E., Rea, M., Holmes, N., Leggett, J., Coles, L.A., Papastavrou, M., Everton, S.K., Hunt, B.A.E., Sims, D., et al (2020). Multi-channel whole-head OPM-MEG: helmet design and a comparison with a conventional system. Neuroimage 219, 116995. https://doi.org/10.1016/j.neuroimage.2020.116995.

Hirschmann, J., Schoffelen, J.M., Schnitzler, A., and van Gerven, M.A.J. (2017). Parkinsonian rest tremor can be detected accurately based on neuronal oscillations recorded from the subthalamic nucleus. Clin. Neurophysiol. 128: 2029-2036.
Holler, P., Trinka, E., and Holler, Y. (2019). MEEGIPS-A modular EEG investigation and processing system for visual and automated detection of high frequency oscillations. Front. Neuroinf. 13: 20.

Holler, Y., Kutil, R., Klaffenbock, L., Thomschewski, A., Holler, P.M., Bathke, A.C., Jacobs, J., Taylor, A.C., Nardone, R., and Trinka, E. (2015). High-frequency oscillations in epilepsy and surgical outcome. A meta-analysis. Front. Hum. Neurosci. 9: 574.

Huang, C.M., and White, L.E., Jr. (1989). High-frequency components in epileptiform EEG. J. Neurosci. Methods 30: 197-201.

Hussain, S.A., Mathern, G.W., Sankar, R., and Wu, J.Y. (2016) Prospective and "live" fast ripple detection and localization in the operating room: impact on epilepsy surgery outcomes in children. Epilepsy Res. 127: 344-351.

limura, Y., Jones, K., Hattori, K., Okazawa, Y., Noda, A., Hoashi, K., Nonoda, Y., Asano, E., Akiyama, T., Go, C., et al (2017). Epileptogenic high-frequency oscillations skip the motor area in children with multilobar drug-resistant epilepsy. Clin. Neurophysiol. 128: 1197-1205.

livanainen, J., Zetter, R., and Parkkonen, L. (2020). Potential of onscalp MEG: robust detection of human visual gamma-band responses. Hum. Brain Mapp. 41: 150-161.

Ikemoto, S., Hamano, S.I., Yokota, S., Koichihara, R., Hirata, Y., and Matsuura, R. (2018). Enhancement and bilateral synchronization of ripples in atypical benign epilepsy of childhood with centrotemporal spikes. Clin. Neurophysiol. 129: 1920-1925.

Ikemoto, S., Hamano, S.I., Yokota, S., Koichihara, R., Hirata, Y., and Matsuura, R. (2020). High-power, frontal-dominant ripples in absence status epilepticus during childhood. Clin. Neurophysiol. 131: 1204-1209.

Insola, A., Di Lazzaro, V., and Assenza, G. (2019). Cortical inhibitory dysfunction in epilepsia partialis continua: a high frequency oscillation somatosensory evoked potential study. Clin. Neurophysiol. 130: 439-444.

Iwatani, Y., Kagitani-Shimono, K., Tominaga, K., Okinaga, T., Kishima, H., Kato, A., Nagai, T., and Ozono, K. (2012). Ictal high-frequency oscillations on scalp EEG recordings in symptomatic West syndrome. Epilepsy Res. 102: 60-70.

Jacobs, J., Staba, R., Asano, E., Otsubo, H., Wu, J.Y., Zijlmans, M., Mohamed, I., Kahane, P., Dubeau, F., Navarro, V., et al (2012). High-frequency oscillations (HFOs) in clinical epilepsy. Prog. Neurobiol. 98: 302-315.

Jiang, W., Wu, C., Xiang, J., Miao, A., Qiu, W., Tang, L., Huang, S., Chen, Q., Hu, Z., and Wang, X. (2019). Dynamic neuromagnetic network changes of seizure termination in absence epilepsy: a magnetoencephalography study. Front. Neurol. 10: 703.

Jirsch, J.D., Urrestarazu, E., LeVan, P., Olivier, A., Dubeau, F., and Gotman, J. (2006). High-frequency oscillations during human focal seizures. Brain 129: 1593-1608.

Kerber, K., Dumpelmann, M., Schelter, B., Le Van, P., Korinthenberg, R., Schulze-Bonhage, A., and Jacobs, J. (2014). Differentiation of specific ripple patterns helps to identify epileptogenic areas for surgical procedures. Clin. Neurophysiol. 125: 1339-1345.

Kerber, K., LeVan, P., Dumpelmann, M., Fauser, S., Korinthenberg, R., Schulze-Bonhage, A., and Jacobs, J. (2013). High frequency oscillations mirror disease activity in patients with focal cortical dysplasia. Epilepsia 54: 1428-1436.

Kobayashi, K., Akiyama, T., Oka, M., Endoh, F., and Yoshinaga, H. (2015). A storm of fast $(40-150 \mathrm{~Hz})$ oscillations during hypsarrhythmia in West syndrome. Ann. Neurol. 77: 58-67. 
Kobayashi, K., Akiyama, T., Oka, M., Endoh, F., and Yoshinaga, H. (2016). Fast $(40-150 \mathrm{~Hz})$ oscillations are associated with positive slow waves in the ictal EEGs of epileptic spasms in West syndrome. Brain Dev. 38: 909-914.

Kobayashi, K., Inoue, T., Watanabe, Y., Oka, M., Endoh, F., Yoshinaga, H., and Ohtsuka, Y. (2009). Spectral analysis of EEG gamma rhythms associated with tonic seizures in Lennox-Gastaut syndrome. Epilepsy Res. 86: 15-22.

Kobayashi, K., Ohuchi, Y., Shibata, T., Hanaoka, Y., Akiyama, M., Oka, M., Endoh, F., and Akiyama, T. (2018). Detection of fast (40$150 \mathrm{~Hz})$ oscillations from the ictal scalp EEG data of myoclonic seizures in pediatric patients. Brain Dev. 40: 397-405.

Kobayashi, K., Oka, M., Akiyama, T., Inoue, T., Abiru, K., Ogino, T., Yoshinaga, H., Ohtsuka, Y., and Oka, E. (2004). Very fast rhythmic activity on scalp EEG associated with epileptic spasms. Epilepsia 45: 488-496.

Kobayashi, K., Watanabe, Y., Inoue, T., Oka, M., Yoshinaga, H., and Ohtsuka, Y. (2010). Scalp-recorded high-frequency oscillations in childhood sleep-induced electrical status epilepticus. Epilepsia 51: 2190-2194.

Kobayashi, K., Yoshinaga, H., Toda, Y., Inoue, T., Oka, M., and Ohtsuka, Y. (2011). High-frequency oscillations in idiopathic partial epilepsy of childhood. Epilepsia 52: 1812-1819.

Kramer, M.A., Ostrowski, L.M., Song, D.Y., Thorn, E.L., Stoyell, S.M., Parnes, M., Chinappen, D., Xiao, G., Eden, U.T., Staley, K.J., et al (2019). Scalp recorded spike ripples predict seizure risk in childhood epilepsy better than spikes. Brain 142: 1296-1309.

Kuhnke, N., Klus, C., Dumpelmann, M., Schulze-Bonhage, A., and Jacobs, J. (2019). Simultaneously recorded intracranial and scalp high frequency oscillations help identify patients with poor postsurgical seizure outcome. Clin. Neurophysiol. 130: 128-137.

Kuhnke, N., Schwind, J., Dumpelmann, M., Mader, M., SchulzeBonhage, A., and Jacobs, J. (2018). High frequency oscillations in the ripple band $(80-250 \mathrm{~Hz})$ in scalp EEG: higher density of electrodes allows for better localization of the seizure onset zone. Brain Topogr. 31: 1059-1072.

Leiken, K.A., Xiang, J., Curry, E., Fujiwara, H., Rose, D.F., Allen, J.R., Kacperski, J.E., O’Brien, H.L., Kabbouche, M.A., Powers, S.W., et al (2016). Quantitative neuromagnetic signatures of aberrant cortical excitability in pediatric chronic migraine. J. Headache Pain 17: 46

Leung, H., Zhu, C.X., Chan, D.T., Poon, W.S., Shi, L., Mok, V.C., and Wong, L.K. (2015). Ictal high-frequency oscillations and hyperexcitability in refractory epilepsy. Clin. Neurophysiol. 126: 2049-2057.

Leung, H.W., Poon, W.S., Kwan, P.K., Lui, C.H., Poon, T.L., Chan, E.L., and Yuen, S.C. (2018). Ictal intracranial electroencephalography using wavelet analysis of high-frequency oscillations in Chinese patients with refractory epilepsy. Hong Kong Med. J. 24: 21-23.

Lin, C.H., Tierney, T.M., Holmes, N., Boto, E., Leggett, J., Bestmann, S., Bowtell, R., Brookes, M.J., Barnes, G.R., and Miall, R.C. (2019). Using optically pumped magnetometers to measure magnetoencephalographic signals in the human cerebellum. J. Physiol. 597: 4309-4324.

Liu, C., Zhang, R., Zhang, G., Yu, T., Tai, J., Du, W., Li, L., and Wang, Y. (2016). High frequency oscillations for lateralizing suspected bitemporal epilepsy. Epilepsy Res. 127: 233-240.

Liu, S., Gurses, C., Sha, Z., Quach, M.M., Sencer, A., Bebek, N., Curry, D.J., Prabhu, S., Tummala, S., Henry, T.R., et al (2018).
Stereotyped high-frequency oscillations discriminate seizure onset zones and critical functional cortex in focal epilepsy. Brain 141: 713-730.

Liu, S., Ince, N.F., Abosch, A., Henry, T.R., and Sha, Z. (2015). Investigation of automatically detected high frequency oscillations (HFOs) as an early predictor of seizure onset zone. Conf. Proc. IEEE Eng. Med. Biol. Soc.: 6602-6605, 2015.

Lu, Y., Worrell, G.A., Zhang, H.C., Yang, L., Brinkmann, B., Nelson, C., and He, B. (2014). Noninvasive imaging of the high frequency brain activity in focal epilepsy patients. IEEE Trans. Biomed. Eng. 61: 1660-1667.

Malinowska, U., Bergey, G.K., Harezlak, J., and Jouny, C.C. (2015). Identification of seizure onset zone and preictal state based on characteristics of high frequency oscillations. Clin. Neurophysiol. 126: 1505-1513.

Matsumoto, A., Brinkmann, B.H., Matthew Stead, S., Matsumoto, J., Kucewicz, M.T., Marsh, W.R., Meyer, F., and Worrell, G. (2013). Pathological and physiological high-frequency oscillations in focal human epilepsy. J. Neurophysiol. 110: 1958-1964.

Melani, F., Zelmann, R., Mari, F., and Gotman, J. (2013). Continuous High Frequency Activity: a peculiar SEEG pattern related to specific brain regions. Clin. Neurophysiol. 124: 1507-1516.

Menendez de la Prida, L., and Trevelyan, A.J. (2011). Cellular mechanisms of high frequency oscillations in epilepsy: on the diverse sources of pathological activities. Epilepsy Res. 97: 308-317.

Meng, L. (2019). A magnetoencephalography study of pediatric interictal neuromagnetic activity changes and brain network alterations caused by epilepsy in the high frequency (801000 Hz). IEEE Trans. Neural Syst. Rehabil. Eng. 27: 389-399.

Miao, A., Xiang, J., Tang, L., Ge, H., Liu, H., Wu, T., Chen, Q., Hu, Z., Lu, $X$., and Wang, X. (2014). Using ictal high-frequency oscillations $(80-500 \mathrm{~Hz})$ to localize seizure onset zones in childhood absence epilepsy: a MEG study. Neurosci. Lett. 566: 21-26.

Migliorelli, C., Alonso, J.F., Romero, S., Nowak, R., Russi, A., and Mananas, M.A. (2017). Automated detection of epileptic ripples in MEG using beamformer-based virtual sensors. J. Neural. Eng. 14: 046013.

Modur, P.N., Zhang, S., and Vitaz, T.W. (2011). Ictal high-frequency oscillations in neocortical epilepsy: implications for seizure localization and surgical resection. Epilepsia 52: 1792-1801.

Mooij, A.H., Frauscher, B., Goemans, S.A.M., Huiskamp, G.J.M., Braun, K.P.J., and Zijlmans, M. (2018). Ripples in scalp EEGs of children: co-occurrence with sleep-specific transients and occurrence across sleep stages. Sleep 41. https://doi.org/10. 1093/sleep/zsy169.

Mooij, A.H., Raijmann, R., Jansen, F.E., Braun, K.P.J., and Zijlmans, M. (2017). Physiological ripples $(+/-100 \mathrm{~Hz})$ in spike-free scalp EEGs of children with and without epilepsy. Brain Topogr. 30: 739-746.

Mouthaan, B.E., Rados, M., Barsi, P., Boon, P., Carmichael, D.W., Carrette, E., Craiu, D., Cross, J.H., Diehl, B., Dimova, P., et al (2016). Current use of imaging and electromagnetic source localization procedures in epilepsy surgery centers across Europe. Epilepsia 57: 770-776.

Murai, T., Hitomi, T., Matsuhashi, M., Matsumoto, R., Kawamura, Y., Kanda, M., Takahashi, R., and Ikeda, A. (2020). Scalp EEG could record both ictal direct current shift and high-frequency oscillation together even with a time constant of 2 seconds. J. Clin. Neurophysiol. 37: 191-194. 
Nagasawa, T., Juhasz, C., Rothermel, R., Hoechstetter, K., Sood, S., and Asano, E. (2012). Spontaneous and visually driven highfrequency oscillations in the occipital cortex: intracranial recording in epileptic patients. Hum. Brain Mapp. 33: 569-583.

Nariai, H., Nagasawa, T., Juhasz, C., Sood, S., Chugani, H.T., and Asano, E. (2011). Statistical mapping of ictal high-frequency oscillations in epileptic spasms. Epilepsia 52: 63-74.

Nardelli, N.V., Krzyzewski, S.P., and Knappe, S.A. (2019). Reducing crosstalk in optically-pumped magnetometer arrays. Phys. Med. Biol. 64: 21NT03.

Navarrete, M., Alvarado-Rojas, C., Le Van Quyen, M., and Valderrama, M. (2016). RIPPLELAB: a comprehensive application for the detection, analysis and classification of high frequency oscillations in electroencephalographic signals. PloS One 11: e0158276.

Nevalainen, P., von Ellenrieder, N., Klimes, P., Dubeau, F., Frauscher, B., and Gotman, J. (2020). Association of fast ripples on intracranial EEG and outcomes after epilepsy surgery. Neurology.

Nissen, I.A., van Klink, N.E., Zijlmans, M., Stam, C.J., and Hillebrand, A. (2016). Brain areas with epileptic high frequency oscillations are functionally isolated in MEG virtual electrode networks. Clin. Neurophysiol. 127: 2581-2591.

Nonoda, Y., Miyakoshi, M., Ojeda, A., Makeig, S., Juhasz, C., Sood, S., and Asano, E. (2016). Interictal high-frequency oscillations generated by seizure onset and eloquent areas may be differentially coupled with different slow waves. Clin. Neurophysiol. 127: 2489-2499.

Ohuchi, Y., Akiyama, T., Matsuhashi, M., and Kobayashi, K. (2019). High-frequency oscillations in a spectrum of pediatric epilepsies characterized by sleep-activated spikes in scalp EEG. Clin. Neurophysiol. 130: 1971-1980.

Ortiz, F., Zapfe, W.P.K., Draguhn, A., and Gutierrez, R. (2018). Early appearance and spread of fast ripples in the Hippocampus in a model of cortical traumatic brain injury. J. Neurosci. 38: 9034-9046.

Pail, M., Halamek, J., Daniel, P., Kuba, R., Tyrlikova, I., Chrastina, J., Jurak, P., Rektor, I., and Brazdil, M. (2013). Intracerebrally recorded high frequency oscillations: simple visual assessment versus automated detection. Clin. Neurophysiol. 124: 1935-1942.

Pail, M., Rehulka, P., Cimbalnik, J., Dolezalova, I., Chrastina, J., and Brazdil, M. (2017). Frequency-independent characteristics of high-frequency oscillations in epileptic and non-epileptic regions. Clin. Neurophysiol. 128: 106-114.

Peng, S.J., Chou, C.C., Yu, H.Y., Chen, C., Yen, D.J., Kwan, S.Y., Hsu, S.P.C., Lin, C.F., Chen, H.H., and Lee, C.C. (2018). Ictal networks of temporal lobe epilepsy: views from high-frequency oscillations in stereoelectroencephalography. J. Neurosurg.: 1-9. https://doi.org/10.3171/2018.6.JNS172844.

Petersson, P., Halje, P., and Cenci, M.A. (2019). Significance and translational value of high-frequency cortico-basal ganglia oscillations in Parkinson's disease. J. Parkinsons Dis. 9: 183-196.

Pizzo, F., Ferrari-Marinho, T., Amiri, M., Frauscher, B., Dubeau, F., and Gotman, J. (2016). When spikes are symmetric, ripples are not: bilateral spike and wave above $80 \mathrm{~Hz}$ in focal and generalized epilepsy. Clin. Neurophysiol. 127: 1794-1802.

Pizzo, F., Frauscher, B., Ferrari-Marinho, T., Amiri, M., Dubeau, F., and Gotman, J. (2016). Detectability of fast ripples $(>250 \mathrm{~Hz})$ on the scalp EEG: a proof-of-principle study with subdermal electrodes. Brain Topogr. 29: 358-367.

Ramachandrannair, R., Ochi, A., Imai, K., Benifla, M., Akiyama, T., Holowka, S., Rutka, J.T., Snead, O.C., 3rd, and Otsubo, H. (2008). Epileptic spasms in older pediatric patients: MEG and ictal highfrequency oscillations suggest focal-onset seizures in a subset of epileptic spasms. Epilepsy Res. 78: 216-224.

Rampp, S., Kaltenhauser, M., Weigel, D., Buchfelder, M., Ingmar Blumcke, I., Dorfler, A., and Stefan, H. (2010). MEG correlates of epileptic high gamma oscillations in invasive EEG. Epilepsia 51: 1638-1642.

Papadelis, C., Tamilia, E., Stufflebeam, S., Grant, P.E., Madsen, J.R., Pearl, P.L., and Tanaka, N. (2016). Interictal high frequency oscillations detected with simultaneous magnetoencephalography and electroencephalography as biomarker of pediatric epilepsy. JoVE 118: 54883.

Ren, S., Gliske, S.V., Brang, D., and Stacey, W.C. (2019). Redaction of false high frequency oscillations due to muscle artifact improves specificity to epileptic tissue. Clin. Neurophysiol. 130: 976-985.

Roehri, N., Lina, J.M., Mosher, J.C., Bartolomei, F., and Benar, C.G. (2016). Time-frequency strategies for increasing high-frequency oscillation detectability in intracerebral EEG. IEEE Trans. Biomed. Eng. 63: 2595-2606.

Qian, P., Li, H., Xue, J., and Yang, Z. (2016). Scalp-recorded highfrequency oscillations in atypical benign partial epilepsy. Clin. Neurophysiol. 127: 3306-3313.

Sakuraba, R., Iwasaki, M., Okumura, E., Jin, K., Kakisaka, Y., Kato, K., Tominaga, T., and Nakasato, N. (2016). High frequency oscillations are less frequent but more specific to epileptogenicity during rapid eye movement sleep. Clin. Neurophysiol. 127: 179-186.

Salami, P., Levesque, M., Gotman, J., and Avoli, M. (2012). A comparison between automated detection methods of highfrequency oscillations $(80-500 \mathrm{~Hz})$ during seizures. J. Neurosci. Methods 211: 265-271.

Schirrmeister, R.T., Springenberg, J.T., Fiederer, L.D.J., Glasstetter, M., Eggensperger, K., Tangermann, M., Hutter, F., Burgard, W., and Ball, T. (2017). Deep learning with convolutional neural networks for EEG decoding and visualization. Hum. Brain Mapp. 38: 5391-5420.

Shi, Q., Zhang, T., Miao, A., Sun, J., Sun, Y., Chen, Q., Hu, Z., Xiang, J., and Wang, X. (2019). Differences between interictal and ictal generalized spike-wave discharges in childhood absence epilepsy: a MEG study. Front. Neurol. 10: 1359.

Spring, A.M., Pittman, D.J., Aghakhani, Y., Jirsch, J., Pillay, N., BelloEspinosa, L.E., Josephson, C., and Federico, P. (2017). Interrater reliability of visually evaluated high frequency oscillations. Clin. Neurophysiol. 128: 433-441.

Spring, A.M., Pittman, D.J., Aghakhani, Y., Jirsch, J., Pillay, N., BelloEspinosa, L.E., Josephson, C., and Federico, P. (2018). Generalizability of high frequency oscillation evaluations in the ripple band. Front. Neurol. 9: 510.

Staba, R.J., Wilson, C.L., Bragin, A., Fried, I., and Engel, J., Jr. (2002). Quantitative analysis of high-frequency oscillations $(80-500 \mathrm{~Hz})$ recorded in human epileptic hippocampus and entorhinal cortex. J. Neurophysiol. 88: 1743-1752.

Tamilia, E., Dirodi, M., Alhilani, M., Grant, P.E., Madsen, J.R., Stufflebeam, S.M., Pearl, P.L., and Papadelis, C. (2020). Scalp ripples as prognostic biomarkers of epileptogenicity in pediatric surgery. Ann. Clin. Transl. Neurol. 7: 329-342. 
Tang, L., Xiang, J., Huang, S., Miao, A., Ge, H., Liu, H., Wu, D., Guan, Q., Wu, T., Chen, Q., et al (2016). Neuromagnetic high-frequency oscillations correlate with seizure severity in absence epilepsy. Clin. Neurophysiol. 127: 1120-1129.

Tenney, J.R., Fujiwara, H., Horn, P.S., Vannest, J., Xiang, J., Glauser, T.A., and Rose, D.F. (2014). Low- and high-frequency oscillations reveal distinct absence seizure networks. Ann. Neurol. 76: 558-567.

Thomschewski, A., Hincapie, A.S., and Frauscher, B. (2019). Localization of the epileptogenic zone using high frequency oscillations. Front. Neurol. 10: 94.

Toda, Y., Kobayashi, K., Hayashi, Y., Inoue, T., Oka, M., Endo, F., Yoshinaga, H., and Ohtsuka, Y. (2015). High-frequency EEG activity in epileptic encephalopathy with suppression-burst. Brain Dev. 37: 230-236.

Toole, C., Martinez-Juarez, I.E., Gaitanis, J.N., Sunderam, S., Ding, L., DiCecco, J., and Besio, W.G. (2019). Source localization of highfrequency activity in tripolar electroencephalography of patients with epilepsy. Epilepsy Behav. 101: 106519.

Usui, N., Terada, K., Baba, K., Matsuda, K., Nakamura, F., Usui, K., Tottori, T., Umeoka, S., Fujitani, S., Mihara, T., et al (2010). Very high frequency oscillations (over $1000 \mathrm{~Hz}$ ) in human epilepsy. Clin. Neurophysiol. 121: 1825-1831.

Usui, N., Terada, K., Baba, K., Matsuda, K., Nakamura, F., Usui, K., Yamaguchi, M., Tottori, T., Umeoka, S., Fujitani, S., et al (2011). Clinical significance of ictal high frequency oscillations in medial temporal lobe epilepsy. Clin. Neurophysiol. 122: 1693-1700.

Usui, N., Terada, K., Baba, K., Matsuda, K., Usui, K., Tottori, T., Mihara, T., and Inoue, Y. (2015). Significance of very-high-frequency oscillations (over $1,000 \mathrm{~Hz}$ ) in epilepsy. Ann. Neurol. 78: 295-302.

van 't Klooster, M.A., Leijten, F.S., Huiskamp, G., Ronner, H.E., Baayen, J.C., van Rijen, P.C., Eijkemans, M.J., Braun, K.P., Zijlmans, M., and group, H.F.O.s. (2015). High frequency oscillations in the intra-operative ECoG to guide epilepsy surgery ("The HFO Trial"): study protocol for a randomized controlled trial. Trials 16: 422.

van 't Klooster, M.A., van Klink, N.E.C., Zweiphenning, W., Leijten, F.S.S., Zelmann, R., Ferrier, C.H., van Rijen, P.C., Otte, W.M., Braun, K.P.J., Huiskamp, G.J.M., et al (2017). Tailoring epilepsy surgery with fast ripples in the intraoperative electrocorticogram. Ann. Neurol. 81: 664-676.

van Klink, N., Frauscher, B., Zijlmans, M., and Gotman, J. (2016). Relationships between interictal epileptic spikes and ripples in surface EEG. Clin. Neurophysiol. 127: 143-149.

van Klink, N., Hillebrand, A., and Zijlmans, M. (2016). Identification of epileptic high frequency oscillations in the time domain by using MEG beamformer-based virtual sensors. Clin. Neurophysiol. 127: 197-208.

van Klink, N., Mol, A., Ferrier, C., Hillebrand, A., Huiskamp, G., and Zijlmans, M. (2018). Beamforming applied to surface EEG improves ripple visibility. Clin. Neurophysiol. 129: 101-111.

van Klink, N., Mooij, A., Huiskamp, G., Ferrier, C., Braun, K., Hillebrand, A., and Zijlmans, M. (2019). Simultaneous MEG and EEG to detect ripples in people with focal epilepsy. Clin. Neurophysiol. 130: 1175-1183.

van Klink, N., van Rosmalen, F., Nenonen, J., Burnos, S., Helle, L., Taulu, S., Furlong, P.L., Zijlmans, M., and Hillebrand, A. (2017). Automatic detection and visualisation of MEG ripple oscillations in epilepsy. Neuroimage Clin 15: 689-701. van Klink, N.E., van 't Klooster, M.A., Leijten, F.S., Jacobs, J., Braun, K.P., and Zijlmans, M. (2016). Ripples on rolandic spikes: a marker of epilepsy severity. Epilepsia 57: 1179-1189.

Velmurugan, J., Nagarajan, S.S., Mariyappa, N., Mundlamuri, R.C., Raghavendra, K., Bharath, R.D., Saini, J., Arivazhagan, A., Rajeswaran, J., Mahadevan, A., et al (2019).

Magnetoencephalography imaging of high frequency oscillations strengthens presurgical localization and outcome prediction. Brain 142: 3514-3529.

Velmurugan, J., Nagarajan, S.S., Mariyappa, N., Ravi, S.G., Thennarasu, K., Mundlamuri, R.C., Raghavendra, K., Bharath, R.D., Saini, J., Arivazhagan, A., et al (2018).

Magnetoencephalographic imaging of ictal high-frequency oscillations $(80-200 \mathrm{~Hz})$ in pharmacologically resistant focal epilepsy. Epilepsia 59: 190-202.

von Ellenrieder, N., Andrade-Valenca, L.P., Dubeau, F., and Gotman, J. (2012). Automatic detection of fast oscillations $(40-200 \mathrm{~Hz})$ in scalp EEG recordings. Clin. Neurophysiol. 123: 670-680.

von Ellenrieder, N., Dubeau, F., Gotman, J., and Frauscher, B. (2017). Physiological and pathological high-frequency oscillations have distinct sleep-homeostatic properties. Neuroimage Clin 14: 566-573.

von Ellenrieder, N., Frauscher, B., Dubeau, F., and Gotman, J. (2016a). Interaction with slow waves during sleep improves discrimination of physiologic and pathologic high-frequency oscillations (80-500 Hz). Epilepsia 57: 869-878.

von Ellenrieder, N., Pellegrino, G., Hedrich, T., Gotman, J., Lina, J.M., Grova, C., and Kobayashi, E. (2016b). Detection and magnetic source imaging of fast oscillations $(40-160 \mathrm{~Hz})$ recorded with magnetoencephalography in focal epilepsy patients. Brain Topogr. 29: 218-231.

Wang, S., Wang, I.Z., Bulacio, J.C., Mosher, J.C., Gonzalez-Martinez, J., Alexopoulos, A.V., Najm, I.M., and So, N.K. (2013). Ripple classification helps to localize the seizure-onset zone in neocortical epilepsy. Epilepsia 54: 370-376.

Wendel, K., Vaisanen, J., Seemann, G., Hyttinen, J., and Malmivuo, J. (2010). The influence of age and skull conductivity on surface and subdermal bipolar EEG leads. Comput. Intell. Neurosci. 2010: 397272.

Worrell, G.A., Gardner, A.B., Stead, S.M., Hu, S., Goerss, S., Cascino, G.J., Meyer, F.B., Marsh, R., and Litt, B. (2008). High-frequency oscillations in human temporal lobe: simultaneous microwire and clinical macroelectrode recordings. Brain 131: 928-937.

Xiang, J., Degrauw, X., Korman, A.M., Allen, J.R., O’Brien, H.L., Kabbouche, M.A., Powers, S.W., and Hershey, A.D. (2013a). Neuromagnetic abnormality of motor cortical activation and phases of headache attacks in childhood migraine. PloS One 8: e83669.

Xiang, J., deGrauw, X., Korostenskaja, M., Korman, A.M., O’Brien, H.L., Kabbouche, M.A., Powers, S.W., and Hershey, A.D. (2013b). Altered cortical activation in adolescents with acute migraine: a magnetoencephalography study. J. Pain 14: 1553-1563.

Xiang, J., Korostenskaja, M., Molloy, C., deGrauw, X., Leiken, K., Gilman, C., Meinzen-Derr, J., Fujiwara, H., Rose, D.F., Mitchell, T., et al (2016a). Multi-frequency localization of aberrant brain activity in autism spectrum disorder. Brain Dev. 38: 82-90.

Xiang, J., Leiken, K., Degrauw, X., Kay, B., Fujiwara, H., Rose, D.F., Allen, J.R., Kacperski, J.E., O'Brien, H.L., Kabbouche, M.A., et al (2016b). Spatial heterogeneity of cortical excitability in migraine 
revealed by multifrequency neuromagnetic signals. J. Pain 17 : 694-706.

Xiang, J., Liu, Y., Wang, Y., Kirtman, E.G., Kotecha, R., Chen, Y., Huo, X., Fujiwara, H., Hemasilpin, N., Lee, K., et al (2009). Frequency and spatial characteristics of high-frequency neuromagnetic signals in childhood epilepsy. Epileptic Disord. 11: 113-125.

Xiang, J., Tenney, J.R., Korman, A.M., Leiken, K., Rose, D.F., Harris, E., Yuan, W., Horn, P.S., Holland, K., Loring, D.W., et al (2015). Quantification of interictal neuromagnetic activity in absence epilepsy with accumulated source imaging. Brain Topogr. 28: 904-914.

Xiang, J., Wang, Y., Chen, Y., Liu, Y., Kotecha, R., Huo, X., Rose, D.F., Fujiwara, H., Hemasilpin, N., Lee, K., et al (2010). Noninvasive localization of epileptogenic zones with ictal high-frequency neuromagnetic signals. J. Neurosurg. Pediatr. 5: 113-122.

Yin, C., Zhang, X., Chen, Z., Li, X., Wu, S., Lv, P., and Wang, Y. (2019). Detection and localization of interictal ripples with magnetoencephalography in the presurgical evaluation of drugresistant insular epilepsy. Brain Res. 1706: 147-156.

Yin, C., Zhang, X., Xiang, J., Chen, Z., Li, X., Wu, S., Lv, P., and Wang, Y. (2020). Altered effective connectivity network in patients with insular epilepsy: a high-frequency oscillations magnetoencephalography study. Clin. Neurophysiol. 131: 377-384.

Zelmann, R., Lina, J.M., Schulze-Bonhage, A., Gotman, J., and Jacobs, J. (2014). Scalp EEG is not a blur: it can see high frequency oscillations although their generators are small. Brain Topogr. 27: 683-704.

Zhang, J., Yang, H., Wu, D., Yang, C., Yang, Y., Zhou, W., Zhang, X., and Sun, W. (2020). Electroencephalographic abnormalities are correlated with cognitive deficits in children with benign childhood epilepsy with centrotemporal spikes: a clinical study of 61 cases. Epilepsy Behav. 106: 107012.

Zijlmans, M., Jacobs, J., Kahn, Y.U., Zelmann, R., Dubeau, F., and Gotman, J. (2011). Ictal and interictal high frequency oscillations in patients with focal epilepsy. Clin. Neurophysiol. 122: 664-671.

Zijlmans, M., Jiruska, P., Zelmann, R., Leijten, F.S., Jefferys, J.G., and Gotman, J. (2012). High-frequency oscillations as a new biomarker in epilepsy. Ann. Neurol. 71: 169-178.

Zijlmans, M., Worrell, G.A., Dumpelmann, M., Stieglitz, T., Barborica, A., Heers, M., Ikeda, A., Usui, N., and Le Van Quyen, M. (2017). How to record high-frequency oscillations in epilepsy: a practical guideline. Epilepsia 58: 1305-1315. 